\title{
Article
}

\section{Impact of the Vertical Component of Earthquake Ground Motion in the Performance Level of Steel Buildings}

\author{
Jesús-Gerardo Valdés-Vázquez ${ }^{1, *(1)}$, Adrián David García-Soto ${ }^{1}\left(\mathbb{D}\right.$ and Miguel Á. Jaimes ${ }^{2} \mathbb{C}$ \\ 1 Department of Civil and Environmental Engineering, Universidad de Guanajuato, Juárez 77, Zona Centro, \\ Guanajuato, Gto. 36000, Mexico; adgarcia@ugto.mx \\ 2 Instituto de Ingeniería, UNAM, Coordinación de Ingeniería Estructural, Av. Universidad, No. 3000, \\ Coyoacán, Mexico City C.P. 04510, Mexico; mjaimest@iingen.unam.mx \\ * Correspondence: valdes@ugto.mx; Tel.: +52-473-1020-100 (ext. 2216)
}

Citation: Valdés-Vázquez, J.-G.; García-Soto, A.D.; Jaimes, M.Á. Impact of the Vertical Component of Earthquake Ground Motion in the Performance Level of Steel Buildings. Appl. Sci. 2021, 11, 1925.

https://doi.org/10.3390/app11041925

Academic Editors: Andrea Paglietti and Maria Favvata

Received: 30 December 2020

Accepted: 19 February 2021

Published: 22 February 2021

Publisher's Note: MDPI stays neutral with regard to jurisdictional claims in published maps and institutional affiliations.

Copyright: (c) 2021 by the authors. Licensee MDPI, Basel, Switzerland. This article is an open access article distributed under the terms and conditions of the Creative Commons Attribution (CC BY) license (https:// creativecommons.org/licenses/by/ $4.0 /)$.
Featured Application: In this work, the non-linear dynamic response of buildings is studied considering both the horizontal component and the vertical component of seismic acceleration records. With an adequate discretization of the structure, it is found that the plastic rotations of the structure can change significantly, which is why the inclusion of the vertical seismic component in the assessment and design of buildings is recommended.

Abstract: This study discusses the impact of the vertical component of earthquake ground motion in the performance level of steel building subjected to earthquake excitations. Analyses are carried out for the strong column-weak beam philosophy because the structural performance is focused on these elements. A realistic steel frame is also considered to investigate the impact of including the seismic vertical component in the non-linear response of the building. The main findings of this study are: (1) When an analysis is performed by considering the horizontal and vertical components of ground motion acting simultaneously (near the causative fault), larger plastic rotations in the beams are obtained as compared to those resulting by considering only the horizontal component. (2) Due to the previous finding, if a codified criterion to inspect the steel beams performance in terms of the plastic rotation is considered, the beam performance could lie within a different acceptation criterion (i.e., from immediate occupancy to collapse prevention) if the vertical component is included in the analysis.

Keywords: non-linear dynamic analysis; seismic response; vertical component; acceptance criteria; steel buildings

\section{Introduction}

It has been reported in the works by Papazoglou et al. [1] and Elnashai et al. [2] that the vertical earthquake ground motion component of some earthquakes located near the causative fault can have an important detrimental impact in the structural behavior of different systems. For instance, Papazoglou et al. [1] attributed seismic failures to the effect of the vertical component of three studied earthquakes on structures. Besides possible compressive overstress or tension failure, the vertical response can lead to failures for the ultimate limit states of flexure moment and shear. The latter (i.e., shear) may explain observed failures perhaps associated with underlying vertical motion effects, because the compression can be reduced, or even mild tension could be reached, decreasing the contribution of concrete to shear resistance. The moment capacity and ductility of reinforced concrete (RC) columns can also be reduced. Unconsidered fluctuations in the axial force due to vertical motions may precipitate flexural failures. In another study, Elnashai et al. [2] based on modal analysis proposed a conservative simple approach to assess vertical seismic forces for buildings. More recently, Kim et al. [3] by means of 
experimental and analytical studies corroborated that the axial load level associated with the seismic vertical component has a detrimental effect on the shear capacity.

The influence of the earthquake ground motion vertical component has been found not only important in the structural response of buildings but also in that of bridges. For instance, Kim et al. [4] evaluated the effect of vertical earthquake ground motion on RC bridge piers and found that the inclusion of the vertical component importantly impacts the response of all components. They concluded that the vertical component should be taken in consideration for bridge design. Likewise, for highway overcrossings, Kunnath et al. [5] found the vertical component of ground motions as a main cause of amplification in the axial force in the columns and flexure moment in the girders. This was reported as especially critical for midspan moments in negative bending. Ancient and historical buildings have also presented damaged attributed to the vertical component of earthquakes, as observed on 7 September 2017 in historical structures located near the epicentral zone of the great Tehuantepec Mw8.2 earthquake, Mexico, Pozos-Estrada et al. [6]; it was suggested that the high frequency contents generated by this event and its vertical component led to damages to belfries, domes, towers and vaults of the historical structures.

On the other hand, it is also reported that when a modal analysis is carried out, different bending moments, axial forces and shear forces are obtained whether the lumped or consistent matrix mass approach is followed, as indicated in Valdés-Vázquez et al. [7], being the structural response (in terms of bending moments and shear forces) significantly increased for the consistent matrix mass approach if the vertical component is included. This is possibly due to the dynamic behavior of beams, which implies carrying loads (due to the vertical component of earthquakes) perpendicular to their longitudinal direction, which in turn causes bending moment and deflections, as cited in Paz et al. [8]. The two approximate methods to consider the inertial effect in the structure in general, and in the beams in particular, are the lumped mass approach (the distributed mass is concentrated in point masses) and the consistent mass approach (the point masses also include rotational effects); this latter method is consistent with the static traverse displacements of the beam, as cited in Paz et al. [8].

In addition, in the studies by Bozorgnia et al. [9] is reported that under certain conditions (i.e., short structural periods, especially for soft soils and near the epicentre) the vertical component becomes much more significant than the horizontal component of ground motion. Besides, it has been pointed out that, specifically for soft soils in the proximity of an active fault in Mexico City, the effects of the vertical component of ground motion should be incorporated in codified design, Jaimes et al. [10]. Other studies including the vertical component are given in [11-17], and some others related to bridge engineering with the vertical component are [18-21].

The effects, damage and possible collapse of structures under the action of the vertical component of ground motion due to earthquakes have been reported in the literature. For instance, the contribution of the vertical component to the response of structures is indicated by Di Sarno et al. [22], who found that the demand due to this component can be significant. The observed evidence, after large seismic events, of structural damage induced by the vertical seismic component is reported for the 1994 Northridge, California and the 1995 Kobe, Japan historical earthquakes [22]. More recently, similar observations are also reported for the 2009 L'Aquila, Italy earthquake [22]; it was indicated that the axial load in reinforced concrete columns was very large (more noticeably in compression), if both components were considered in the seismic analysis. It was stated that both components should be incorporated in the evaluation of the response of building frames, more markedly in the near-fault cases.

Compressions in columns above the balance load, as well as tensions in isolation systems and columns (over the balanced load too) have also been reported for buildings (Mazza et al. [23]) when the horizontal and vertical components of near-source earthquakes are considered. Other study related to seismically isolated systems subjected to seismic excitations from horizontal and vertical components found that including the latter is of 
key importance to designing pendulum isolators for two-degree of freedom systems (Landi et al. [24]). In addition, regarding base-isolated structures (irregular ones with friction pendulum), it has been found that when the vertical component is significant (near-source sites), uplift could occur if the effect of the vertical component is not accounted for (Mazza et al. [25]).

Collapse-prone frame structural types under the action of the seismic vertical component have been identified in terms of the ground motion characteristics, when the structures are subjected to multi-directional excitations (Harrington et al. [26]). The Housner intensity (Housner [27]) can be used to assess the influence of the vertical seismic component in the collapse of structures, especially structures more vulnerable to such component, as buildings with many cantilevered members and buildings which columns are subjected to large load effects.

Therefore, investigating the impact of including the earthquake ground motion vertical component in the earthquake resistant design and analysis of buildings is needed. In this study, the seismic response of steel buildings subjected to horizontal and vertical ground motions during Mexican earthquakes is presented.

The main objective of this study is to assess the impact of including the vertical component of essentially near-fault earthquake ground motions in the performance level of steel beams, by carrying out non-linear dynamic analyses on steel-frame buildings. Comparisons are given against the analysis by considering only the horizontal component, including the case of a steel frame designed by an experienced practicing engineer.

\section{Hypothetical Buildings Considering the Strong-Column Weak-Beam Philosophy}

To establish the framework used in this study, first the seismic response assessment of two hypothetical steel-frame buildings subjected to Mexican ground motions is considered. These structures do not necessarily correspond to minimum requirements from any code, but to structures which follows the strong-column weak-beam philosophy and are expected to exhibit a non-linear behavior under seismic loading. Nevertheless, this framework is applied later to a realistic structure designed by an experienced practicing engineer as per international standards, to validate the findings from a practical design standpoint.

For the hypothetical structures in this section, the considered steel is A-36 according to the American Institute of Steel Construction. In Figure 1 the studied buildings are shown. One is formed by a six-story steel-frame structure with columns W18 $\times 60$ and beams W12 $\times 14$ sections; the showed diagonals are W10 $\times 45$ sections. A uniformly distributed load of $12 \mathrm{kN} / \mathrm{m}$ for all beams is assumed; this load plus the self-weight of the structure is used for calculating the natural vibration periods. The second is a 10-story building frame formed by W18 $\times 211$, W16 $\times 31$ and W10 $\times 45$ sections for the columns, beams and diagonals, respectively. In this case, an $18 \mathrm{kN} / \mathrm{m}$ load is considered for all the beams plus the structure self-weight. The plastic hinges of steel beams to be studied are indicated by red dots in Figure 1; they are selected because the analyses indicated that they are the most critical in terms of plastic rotations (i.e., they are identified after performing all seismic dynamic analyses and rank the rotations in all the buildings). The plastic hinges shown are not the only ones (which also vary depending on the record used). For the comparisons, the study is focused on the plastic hinges with the largest rotations. 

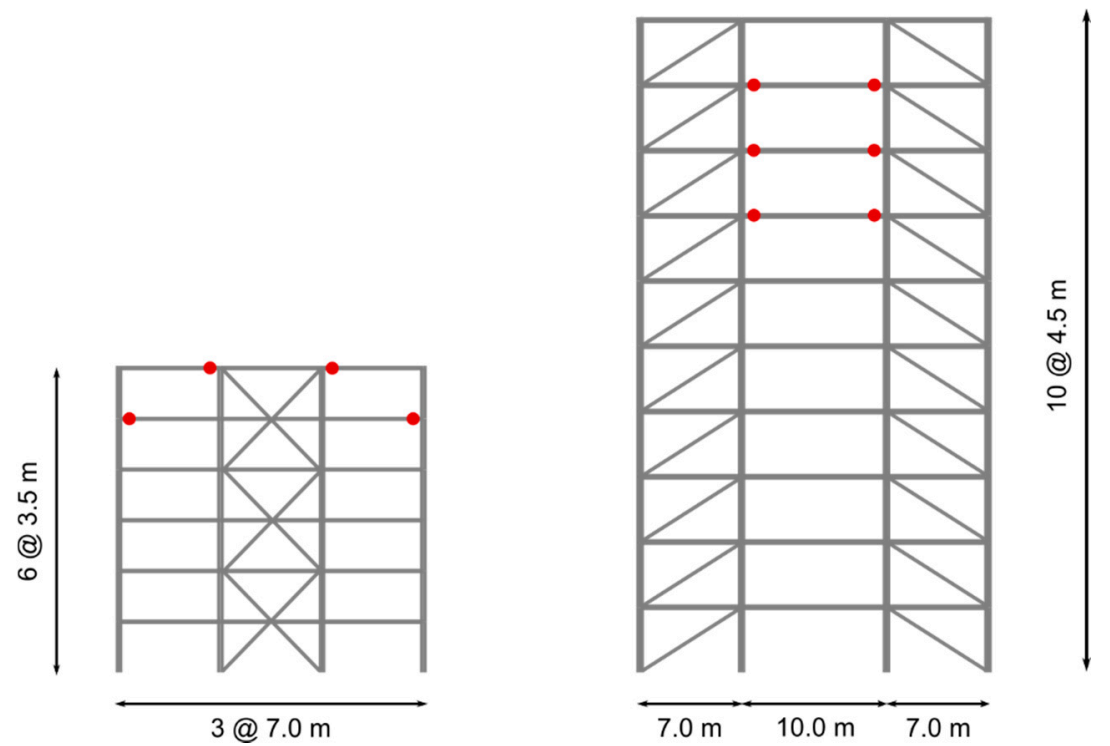

Figure 1. Steel-frame buildings and plastic hinges (red dots) considered.

Although not specific code was used for designing the frames as mentioned before, they correspond to the strong-column weak-beam philosophy contained in many relevant standards (e.g., American Society of Civil Engineers (ASCE 7-16) [28]; IBC-2018 [29]; NTCS-2017 [30]; Eurocode [31]).

For the six-story building, the first horizontal vibration period is $\mathrm{T}_{1 \mathrm{~h}}=0.398 \mathrm{~s}$, the second is $T_{2 h}=0.108 \mathrm{~s}$ and the third one is $\mathrm{T}_{3 \mathrm{~h}}=0.052 \mathrm{~s}$, as shown in Figure 2. The same corresponding periods, but for the vertical response are $\mathrm{T}_{1 \mathrm{v}}=0.173 \mathrm{~s}, \mathrm{~T}_{2 \mathrm{v}}=0.164 \mathrm{~s}$ and $\mathrm{T}_{3 \mathrm{v}}=0.060 \mathrm{~s}$, respectively, as in Figure 3.

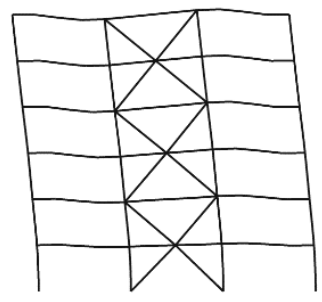

(a) $\mathrm{T}_{1 \mathrm{~h}}=0.398 \mathrm{~s}$

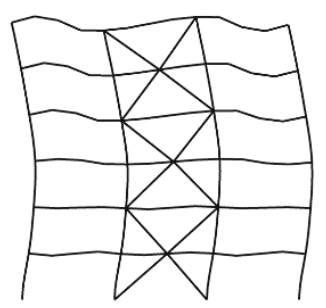

(b) $\mathrm{T}_{2 \mathrm{~h}}=0.108 \mathrm{~s}$

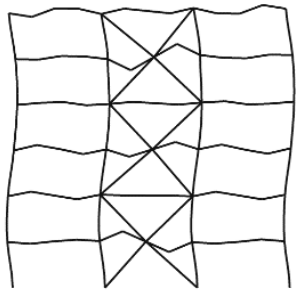

(c) $\mathrm{T}_{3 \mathrm{~h}}=0.052 \mathrm{~s}$

Figure 2. Horizontal vibration modes for the six-story building.

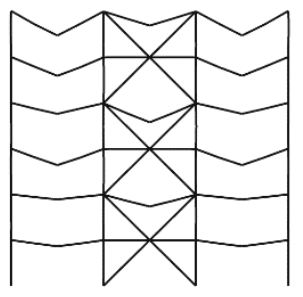

(a) $\mathrm{T}_{1 \mathrm{v}}=0.173 \mathrm{~s}$

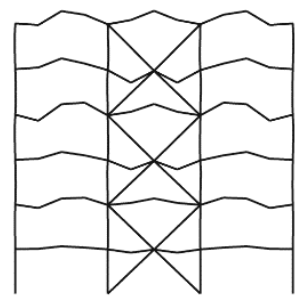

(b) $\mathrm{T}_{2 \mathrm{v}}=0.164 \mathrm{~s}$

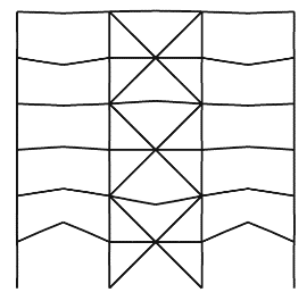

(c) $\mathrm{T}_{3 \mathrm{v}}=0.060 \mathrm{~s}$

Figure 3. Vertical vibration modes for the six-story building.

The computed horizontal and vertical vibration modes in the same order as previously described for the ten-story building are $\mathrm{T}_{1 \mathrm{~h}}=0.841 \mathrm{~s}, \mathrm{~T}_{2 \mathrm{~h}}=0.238 \mathrm{~s}$ and $\mathrm{T}_{3 \mathrm{~h}}=0.121 \mathrm{~s}$, and 
$\mathrm{T}_{1 \mathrm{v}}=0.198 \mathrm{~s}, \mathrm{~T}_{2 \mathrm{v}}=0.122 \mathrm{~s}$ and $\mathrm{T}_{3 \mathrm{v}}=0.058 \mathrm{~s}$, respectively, which are depicted in Figure 4 for the horizontal modes and Figure 5 for the vertical ones.

Based on a previous study by Valdés et al. [7], the frames and elements were selected so that they work in a range $60-80 \%$ of their capacity for gravitational load only. Therefore, when the buildings are subjected to the records reported in Table 1, the inelastic behavior of several elements can be inspected and compared for the one-versus the two-component analyses. Another possibility to guarantee that many members of the structures undergo into the inelastic range is to scale the records. This alternative is recommended in future research using reliable methods and recognizing their limitations. In the last floors, where the member sizes are normally smaller, it has been showed that when the vertical component is added to the horizontal component in the dynamic analysis using consistent masses, the shear forces and bending moments are larger in the upper levels, especially for the roof, which is not normally noticed in regular design (Valdés et al. [7]).

In general terms, two finite element-based formulations to analyze structures are available: the displacement-based formulation and the force-based formulation. For the former an adequate discretization of the structure is required, so that an adequate solution can be captured, whereas for the latter, the right solution is determined solely with one element. Therefore, the force-based formulation is preferred. However, when the vertical seismic component is included, the force-based formulation is insufficient, and an adequate discretization is warranted to accurately obtain the solution. In this study, elements by considering the force-based formulation are used, together with an adequate discretization.

\section{Ground Motions}

In order to capture the influence of the vertical component of earthquake ground motion in the performance level of steel building beams, this study uses different ground motions from Mexico listed in Table 1 (where PGAh and PGAv denote peak ground acceleration for the horizontal and vertical component, respectively) and whose response spectra are shown in Figure 6. These earthquake ground motions were selected to represent significant to non-significant vertical earthquake ground motion values (e.g., PGA $\mathrm{P}_{V}$ from 0.45 to $0.094 \mathrm{~g})$.

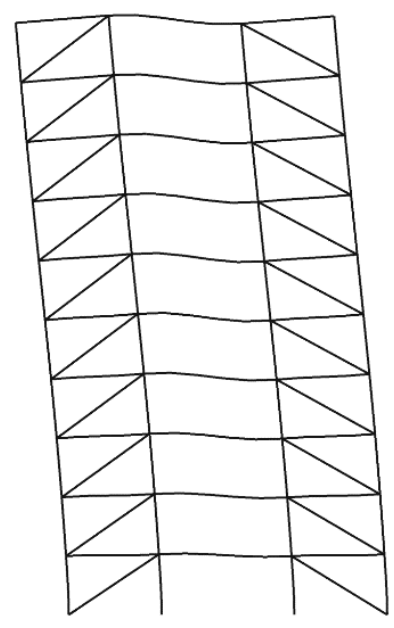

(a) $\mathrm{T}_{1 \mathrm{~h}}=0.841 \mathrm{~s}$

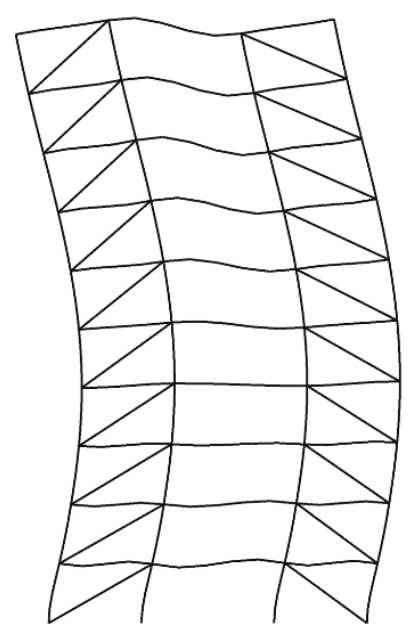

(b) $\mathrm{T}_{2 \mathrm{~h}}=0.238 \mathrm{~s}$

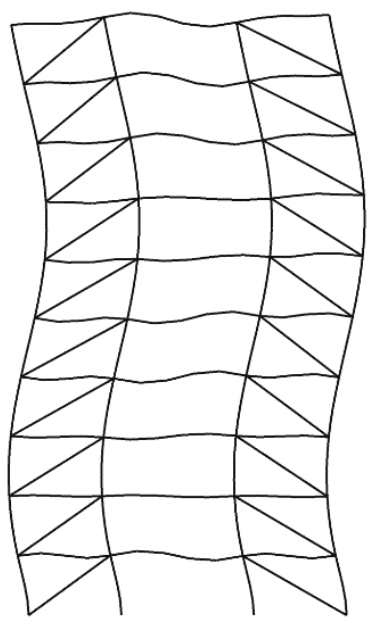

(c) $\mathrm{T}_{3 \mathrm{~h}}=0.121 \mathrm{~s}$

Figure 4. Horizontal vibration modes for the ten-story building. 


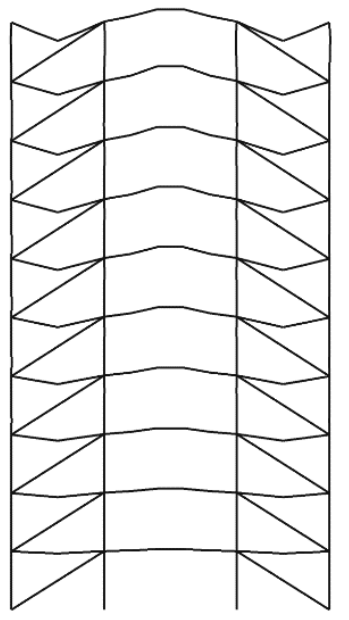

(a) $\mathrm{T}_{1 \mathrm{v}}=0.198 \mathrm{~s}$

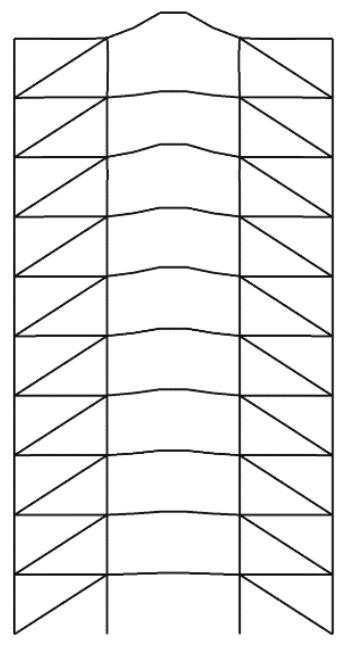

(b) $\mathrm{T}_{2 \mathrm{v}}=0.122 \mathrm{~s}$

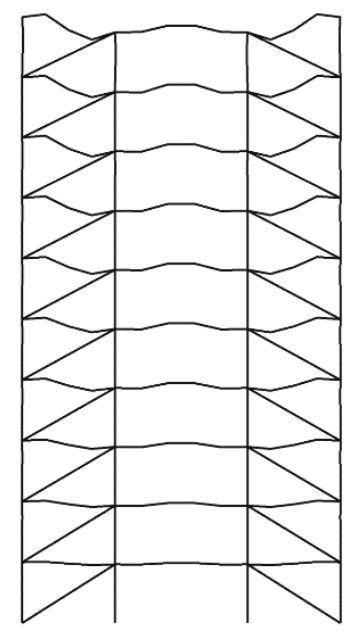

(c) $\mathrm{T}_{3 \mathrm{v}}=0.058 \mathrm{~s}$

Figure 5. Vertical vibration modes for the ten-story building.
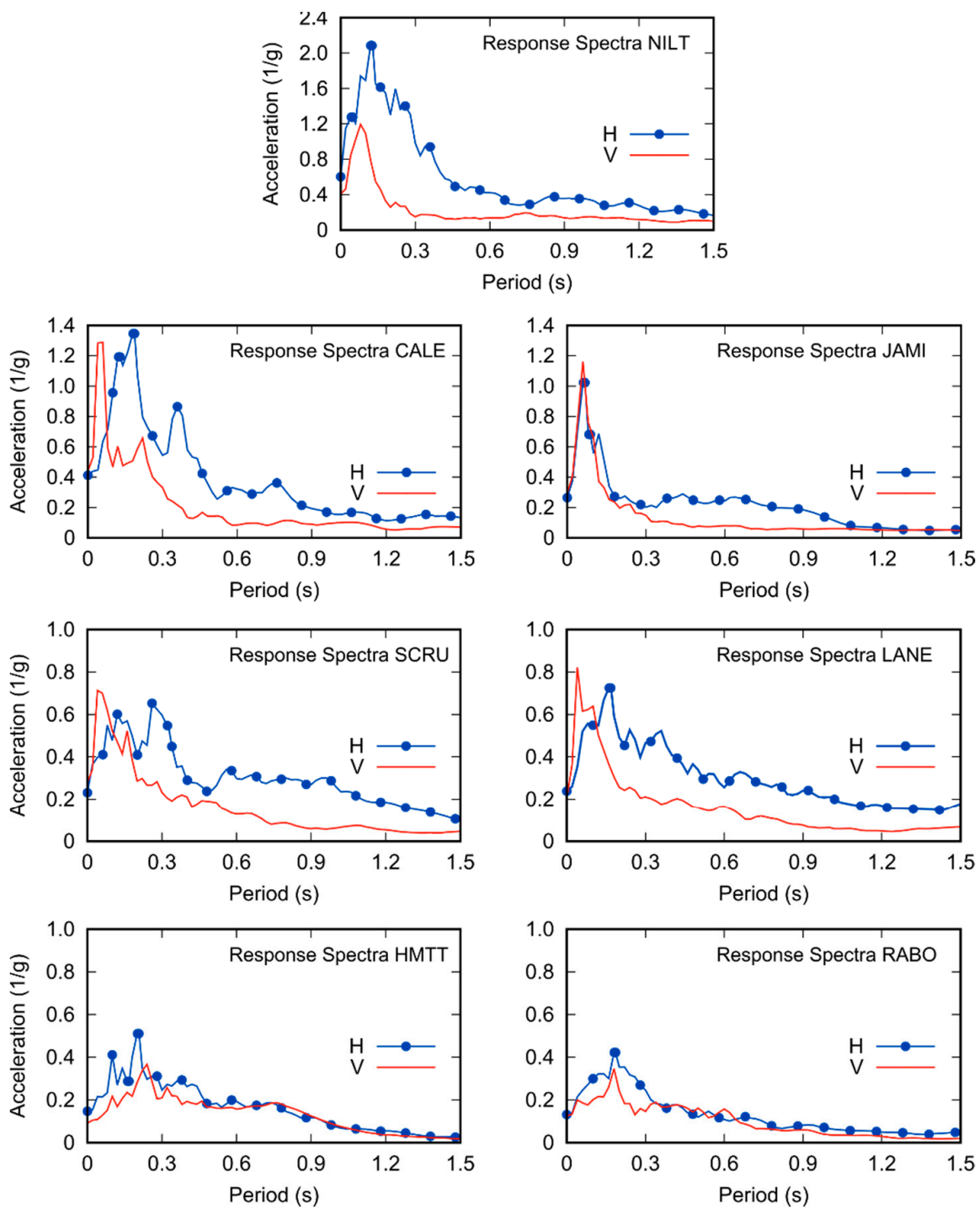

Figure 6. Response spectra used from different stations. 
Table 1. Mexican ground motions used for the frames in Figure 1.

\begin{tabular}{cccccccccc}
\hline${ }^{1}$ Station & Direction & $\begin{array}{c}\text { Date } \\
\text { (YYYY/MM/DD) }\end{array}$ & $\begin{array}{c}\text { Magnitud } \\
\mathbf{M w}\end{array}$ & Rrup (km) & Lat. & Long. & H (km) & PGA $_{\mathbf{h}}(\mathbf{g})$ & PGA $_{\mathbf{v}}(\mathbf{g})$ \\
\hline NILT & NS & $2017 / 09 / 07$ & 8.2 & 100.6 & 14.76 & 94.11 & 58 & 0.498 \\
CALE & EW & $1997 / 01 / 11$ & 7.1 & 25.15 & 17.91 & 103.91 & 40 & 0.404 & 0.449 \\
JAMI & EW & $1999 / 09 / 30$ & 7.4 & 48.74 & 16.03 & 96.96 & 47 & 0.256 \\
SCRU & NS & $2017 / 09 / 07$ & 8.2 & 91.65 & 14.76 & 94.11 & 58 & 0.253 & 0.292 \\
LANE & NS & $1999 / 09 / 30$ & 7.4 & 22.56 & 16.03 & 96.96 & 47 & 0.244 & 0.213 \\
HMTT & EW & $2017 / 09 / 19$ & 7.1 & 48.99 & 18.33 & 98.67 & 57 & 0.147 & 0.094 \\
RABO & NS & $2017 / 09 / 19$ & 7.1 & 14.51 & 18.33 & 98.67 & 57 & 0.132 & 0.120 \\
\hline
\end{tabular}

${ }^{1}$ Stations designations are somewhat arbitrary acronyms of names in Spanish from different accelerometric arrays.

\section{Seismic Structural Response}

For the analysis of the structures, the OpenSEES program [32] was used, together with the pre- and post-processor GiD [33] and the coupling interface between both of them, GiD+OpenSees Platform [34].

They consider distributed plasticity with fibers in all the elements. In the case of beams, the P-delta effect is added. At intersections, the joint offset node with a dimension equal to half the depth of the elements is also considered. At the base, all the columns are fixed in all degrees of freedom and, in the stories, a rigid diaphragm was considered at each level. For the whole structure, the OpenSEES element type force-beam-column was used. The maximum size for the finite element mesh was $0.87 \mathrm{~m}$ for the columns and $1.75 \mathrm{~m}$ for the beams, with the idea of adding intermediate nodes in the elements to capture the vertical modes more accurately. The selected mesh size was determined by inspecting the maximum size for which no further accuracy is gained if more refined mesh sizes are used. Note also that the same mesh size was used in other study by Gremer et al. [15].

The damping ratio was determined through the Rayleigh damping method taking into account the first two horizontal vibration periods of each structure, together with the current stiffness matrix. The used element type from OpenSEES is the force-Beam-Column, considering three Gauss-Lobatto integration points. The material type is Steel02 with a yield stress $\mathrm{Fy}=248.21 \mathrm{MPa}$, initial elastic tangent $\mathrm{E}=200 \mathrm{GPa}$ and a strain-hardening ratio $b=0.01$ (as defined in OpenSEES). A 2D model was used, where first a static analysis under gravity loads was carried out, then the inertial force generated by every record was added in a second step considering a $0.01 \mathrm{~s}$ time step.

In this section, the results from the non-linear dynamic analyses using the records in the previous section are presented. For brevity, only flexure moments for the outermost fiber of the beam sections are depicted in moment-rotation diagrams. The employed

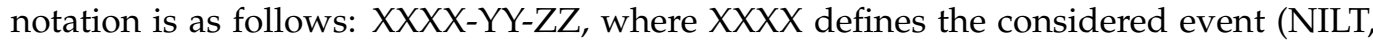
CALE, etc.; e.g., Figure 6), YY the story (e.g., $5 S$ for the 5th story of the building in study) where the most critical studied beam is located and ZZ denotes the side where the considered beam is situated (RS and LS for right and left side, respectively), in agreement with the plastic hinges depicted in Figure 1. In the following, results are first presented for the 6-story building and then for the 10-story building. Note that for the horizontal components in this study, only one of the orthogonal horizontal components is selected. Although every ground motion contains recordings for two horizontal and one vertical (orthogonal) components, the horizontal one leading to the most critical results when the vertical component is added was selected. This not necessarily implies that the most critical horizontal component corresponds to a larger peak ground acceleration.

\subsection{Results for 6-Story Building}

For the 6-story steel-frame structure the most critical plastic hinges are located at Floors 5 and 6 as shown in Figure 1. The W12 $\times 14$ beams in this structure has a yielding flexure moment $\mathrm{My}=60.7 \mathrm{kN}-\mathrm{m}$ and a yielding rotation $\theta \mathrm{y}=0.0109 \mathrm{rad}$. For brevity, $\mathrm{H}$ and $\mathrm{V}$ are used to denote the horizontal and the vertical component, respectively. 
When the 6-story building is subjected to the earthquake recorded at station NILT, the rotations and equivalent values (as function of the yielding rotation) from the non-linear dynamic analyses are $0.0293 \mathrm{rad}(2.69 \theta \mathrm{y})$ for $\mathrm{H}$ and $0.0348 \mathrm{rad}(3.20 \theta \mathrm{y})$ for $\mathrm{H} \& \mathrm{~V}$ (i.e., horizontal and vertical component acting simultaneously). This represents an increase of $18.9 \%$ if the two components are used instead of only H (Figure 7, NILT-5S-RS).
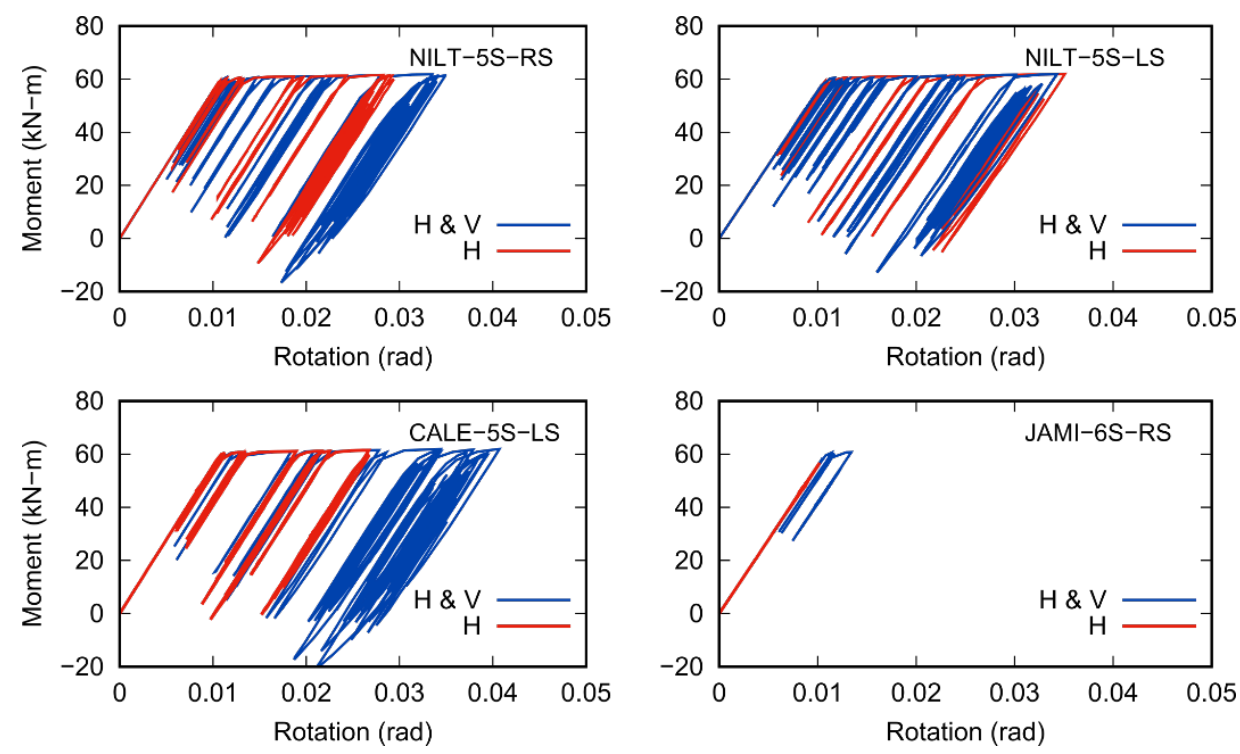

Figure 7. Non-linear response of the outer-most fiber in different beams for different earthquakes; 6-story buildings (Part 1).

As an exceptional response for NILT recording, the rotations and equivalent values considering one or the two components for the non-linear dynamic analysis are $0.0351 \mathrm{rad}$ and $3.22 \theta y(\mathrm{H})$ and $0.0342 \mathrm{rad}$ and $3.15 \theta \mathrm{y}(\mathrm{H} \& \mathrm{~V})$, respectively. In this case the change is $-2.1 \%$ (i.e., the structural response actually decreased for this earthquake when both components were considered). This last result indicates that consideration of both components simultaneously can lead in some cases to less critical results (Figure 7, NILT-5S-LS). This could be explained because in some cases the vertical demand counteracts the horizontal one, for certain elements and under certain excitations, albeit this is not frequent.

For the recording of station CALE, the most critical beam is on the left side of the 5 th floor. When only the horizontal seismic component is considered for the analysis, the maximum rotation value is $0.0268 \mathrm{rad}$, equivalent to $2.46 \theta \mathrm{y}$. On the other hand, when both, the horizontal and the vertical, seismic components are considered, the maximum rotation results in $0.0407 \mathrm{rad}$, equivalent to $3.73 \theta \mathrm{y}$. This means that the maximum rotation increased $51.6 \%$ with respect to that calculated when only the horizontal component is taken into account (Figure 7, CALE-5S-LS).

For the earthquake recording of station JAMI, this time the most critical beam is situated on the left side of the 6th floor (6th story-6S-LS). For the horizontal response, the rotations remain linear with a value of $0.0102 \mathrm{rad}$, equivalent to $0.94 \theta \mathrm{y}$. On the other hand, when both components are considered simultaneously, the rotation is $0.0134 \mathrm{rad}$, which is equivalent to $1.23 \theta y$. This represents a $30.8 \%$ rotation increase, as compared to the horizontal component analysis alone (Figure 7, JAMI-6S-RS).

For the earthquake recorded at station SCRU (Figure 8, SCRU-6S-RS), the most critical beam is located on the right side of the 6th level. In this case for the seismic horizontal component, $0.0100 \mathrm{rad}$ and $0.92 \theta \mathrm{y}$ were obtained. When both components were included, this led to $0.0303 \mathrm{rad}$ and $2.79 \theta \mathrm{y}$, representing a very significant increase of $203.2 \%$ with respect to the single-component analysis. 

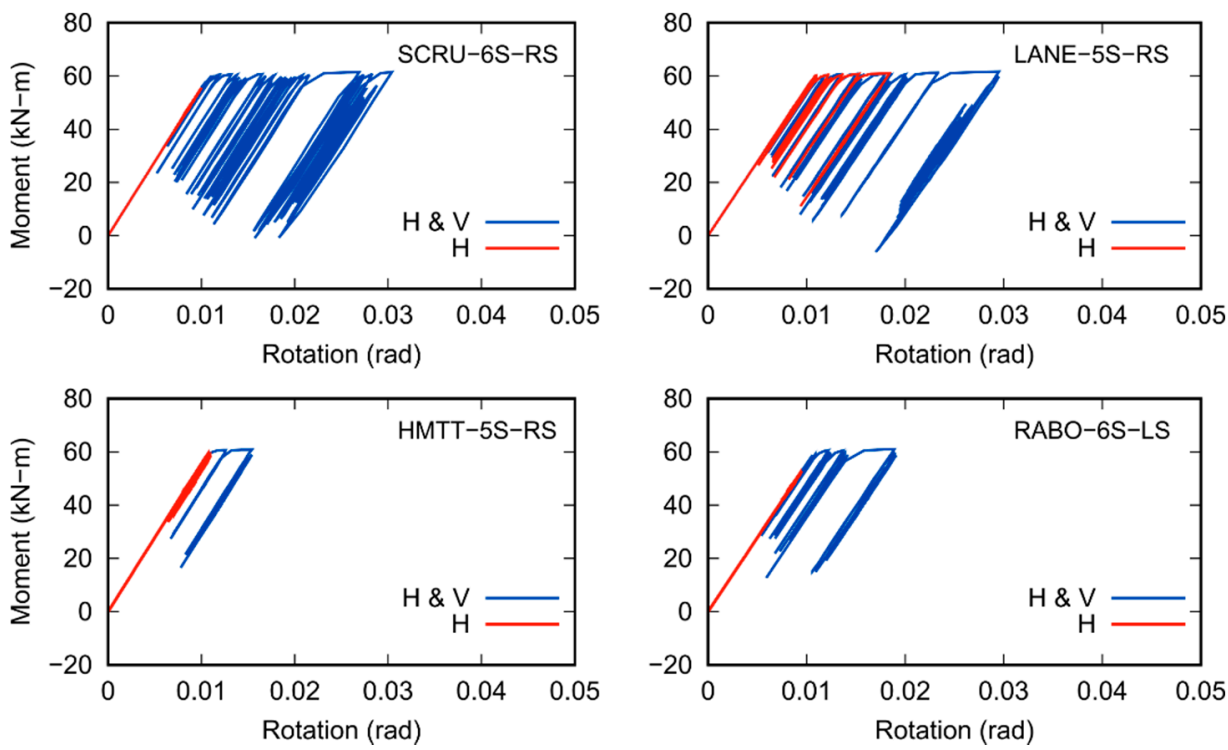

Figure 8. Non-linear response of the outer-most fiber in different beams for different earthquakes; 6-story buildings (part 2).

For the earthquake recording of station LANE, the most critical beam is on the right side in Floor 5. When only the horizontal component is considered, the maximum rotation reaches $0.0183 \mathrm{rad}$, or $1.69 \theta \mathrm{y}$. When both components are included in the analysis, the values are $0.0295 \mathrm{rad}$ and $2.710 \mathrm{y}$, respectively, which represents an increment of $60.3 \%$ in this case (Figure 8, LANE-5S-RS).

For the recording of station HMTT the rotations and equivalent values considering one or the two components for the non-linear dynamic analyses are $0.0110 \mathrm{rad}$ and $1.01 \theta \mathrm{y}$ and $0.0154 \mathrm{rad}$ and $1.41 \theta y$, respectively. This represents an increase of the two-component dynamic analysis in relation to the horizontal component analysis of $39.6 \%$ (Figure 8 , HMTT-5S-RS).

Finally, for earthquake recorded at station RABO (Figure 8, RABO-6S-LS), the most critical beam is located on the left side of the 6th level. In this case, for the horizontal component seismic analysis, $0.0094 \mathrm{rad}$ and $0.87 \theta \mathrm{y}$ were obtained. When both components were included, this led to $0.0191 \mathrm{rad}$ and $1.750 \mathrm{y}$, representing a significant increase of $101.1 \%$.

As a summary, the previous values are listed in Table 2.

Table 2. Rotations generated by horizontal earthquake components and by horizontal and vertical earthquake components acting together (6-story building).

\begin{tabular}{cccccccc}
\hline \multirow{2}{*}{$\begin{array}{c}\text { Rotation } \\
\text { Computed }\end{array}$} & \multicolumn{7}{c}{ Rotation Values for Earthquake Station Register Considered (rad) } \\
\cline { 2 - 8 } & NILT & CALE & JAMI & SCRU & LANE & HMTT & RABO \\
\hline \multirow{2}{*}{$\theta_{h}$} & 0.0293 & 0.0268 & 0.0102 & 0.0100 & 0.0183 & 0.0110 & 0.0094 \\
\multirow{2}{*}{$\theta_{h+v}$} & $(2.69 \theta \mathrm{y})$ & $(2.46 \theta \mathrm{y})$ & $(0.94 \theta \mathrm{y})$ & $(0.92 \theta \mathrm{y})$ & $(1.69 \theta \mathrm{y})$ & $(1.01 \theta \mathrm{y})$ & $(0.87 \theta \mathrm{y})$ \\
& 0.0348 & 0.0407 & 0.0134 & 0.0303 & 0.0295 & 0.0154 & 0.0191 \\
& $(3.20 \theta \mathrm{y})$ & $(3.73 \theta \mathrm{y})$ & $(1.23 \theta \mathrm{y})$ & $(2.79 \theta \mathrm{y})$ & $(2.71 \theta \mathrm{y})$ & $(1.41 \theta \mathrm{y})$ & $(1.75 \theta \mathrm{y})$ \\
\hline
\end{tabular}

Figure 9 shows plastic hinges for JAMI seismic record where the red color indicates that the plastic hinge is formed. The color contour represents the plastic rotation depicted graphically with the GiD+OpenSEES interface, i.e., it shows the zones where the plastic hinges occur. The red/blue color indicates higher/lower degree of plastic rotation. 


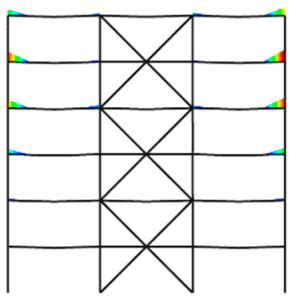

(a) Only horizontal component

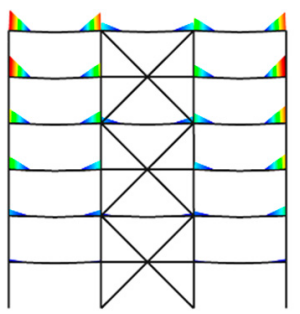

(b) Horizontal and vertical component

Figure 9. Plastic hinges for earthquake JAMI at the end of the seismic register. The red/blue color in the color contours indicates higher/lower degree of plastic rotation.

\subsection{Results for 10-Story Building}

This section is analogous to the previous one but results for the 10-story building are reported. The most critical plastic hinges were found in Levels 7, 8 and 9, as observed in Figure 1.

For the W16 $\times 31$ beams, the yielding flexure moment is My $=192.0 \mathrm{kN}-\mathrm{m}$, with a yielding rotation $\theta y=0.0114 \mathrm{rad}$. Likewise, in Figure 10 rotation diagrams for cases NILT7S-LS and NILT-8S-RS are shown. Their respective values were (again for the one- and two-component analyses) $0.0274 \mathrm{rad}(2.41 \theta \mathrm{y})$ and $0.0377 \mathrm{rad}(3.31 \theta \mathrm{y}), 0.0284 \mathrm{rad}(2.50 \theta \mathrm{y})$ and $0.0353 \mathrm{rad}(3.10 \theta \mathrm{y})$ corresponding to increases of $37.3 \%$ and $24.0 \%$, respectively (i.e., increases with respect to the horizontal component analysis).
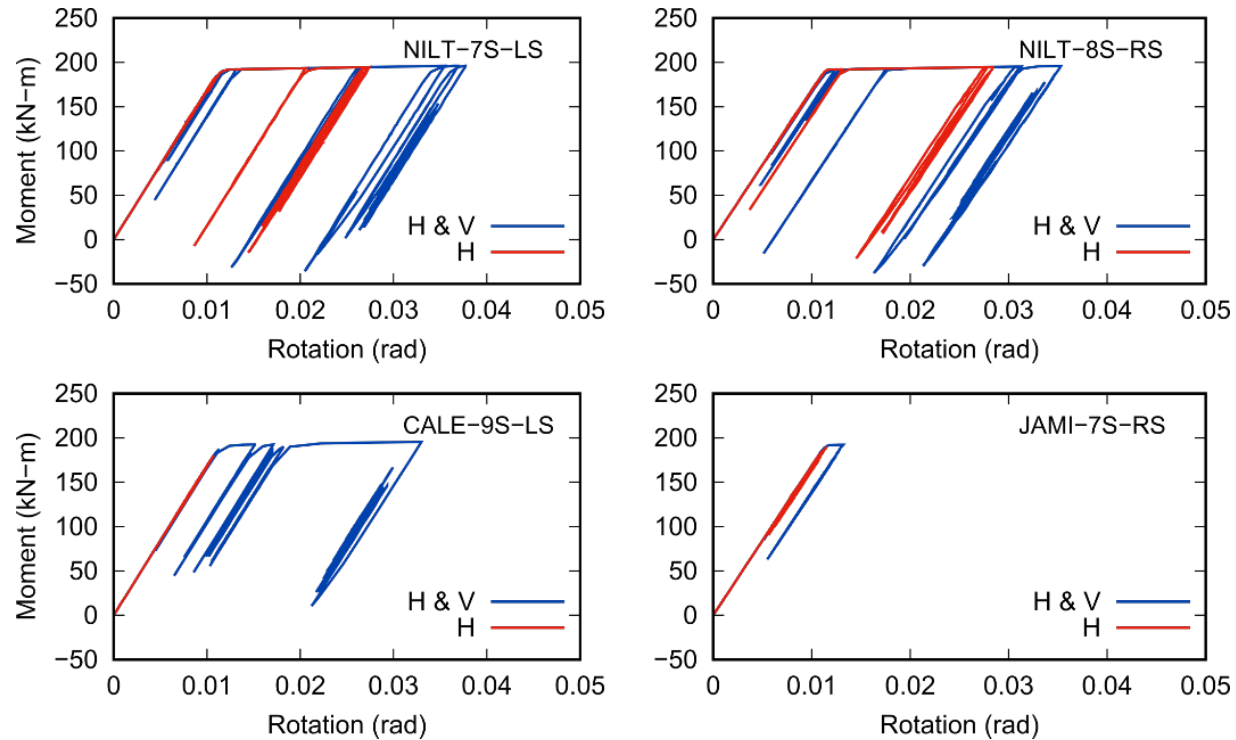

Figure 10. Non-linear response of the outer-most fiber in different beams for different earthquakes; 10-story buildings (Part 1).

For the case CALE-9S-LS, one- and two-component analysis led to rotations of $0.0107 \mathrm{rad}(0.94 \theta \mathrm{y})$ and $0.0330 \mathrm{rad}(2.89 \theta \mathrm{y})$, which is a $207.4 \%$ increase with respect to considering only the horizontal component (Figure 10).

Response to the earthquake for case JAMI-7S-RS depicted in Figure 10, led to $0.0114 \mathrm{rad}$ $(1.0 \theta \mathrm{y})$ and $0.0132 \mathrm{rad}(1.15 \theta \mathrm{y})$ for the one- and two-component analysis, respectively. These values represent an increase of the two-component non-linear dynamic analysis in relation to its one-component counterpart of $15.0 \%$.

Likewise, in Figure 11 rotation diagrams for SCRU-8S-LS are shown. Their respective values were (again for the one- and two-component analyses) $0.0175 \mathrm{rad}(1.54 \theta \mathrm{y})$ and 
$0.0276 \mathrm{rad}(2.42 \theta \mathrm{y})$, corresponding to an increase of $57.1 \%$ (i.e., increase with respect to the horizontal component analysis).
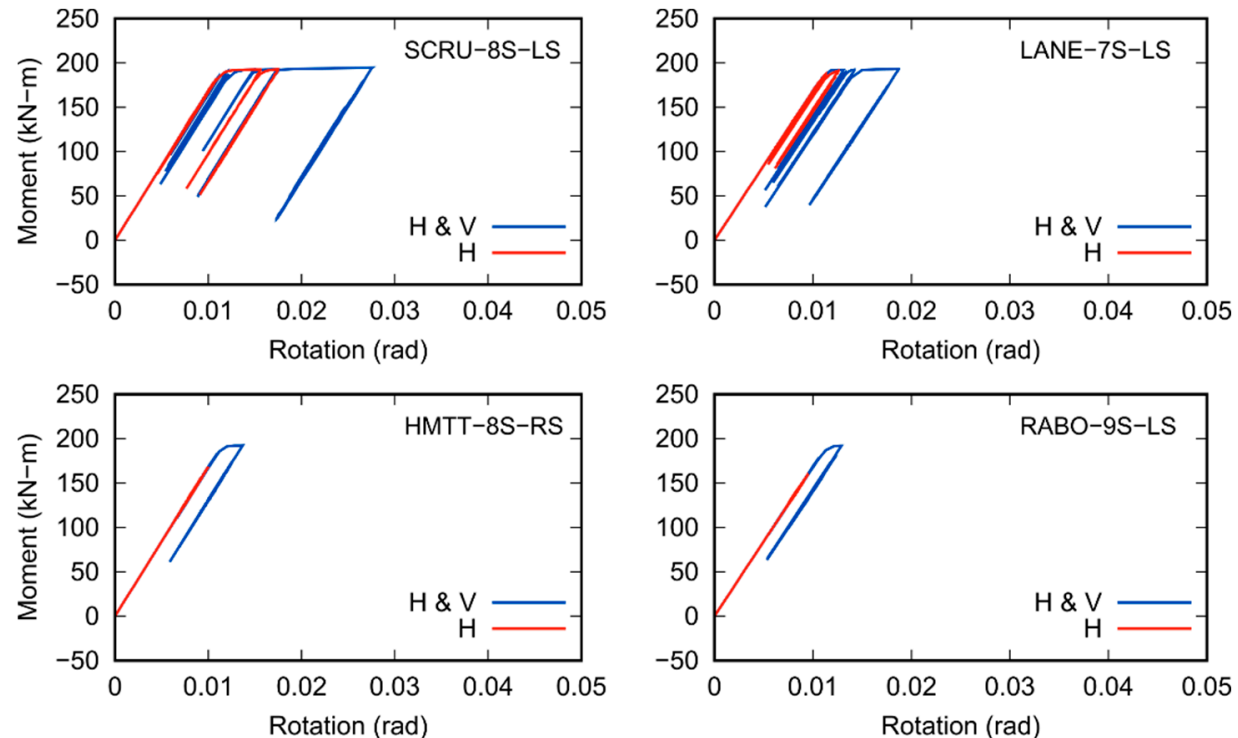

Figure 11. Non-linear response of the outer-most fiber in different beams for different earthquakes; 10-story buildings (Part 2).

The response to the earthquake of station LANE-7S-LS is depicted in Figure 11, led to $0.0130 \mathrm{rad}(1.14 \theta \mathrm{y})$ and $0.0178 \mathrm{rad}(1.56 \theta \mathrm{y})$ for the one- and two-component analysis, respectively. These values represent increases of the two-component non-linear dynamic analyses in relation to their one-component counterparts of $36.8 \%$.

Response to the earthquake for case HMTT-8S-RS depicted in Figure 11, led to $0.0100 \mathrm{rad}(0.88 \theta \mathrm{y})$ and $0.0137 \mathrm{rad}(1.20 \theta \mathrm{y})$ for the one- and two-component analysis, respectively. These values represent increases of the two-component non-linear dynamic analyses in relation to their one-component counterparts of $36.3 \%$.

Likewise, in Figure 11 rotation diagrams for earthquake response for the case RABO9S-LS are shown. Their respective values were (again for the one- and two-component analyses) $0.0095 \mathrm{rad}(0.84 \theta \mathrm{y})$ and $0.0129 \mathrm{rad}(1.13 \theta \mathrm{y})$ corresponding to increases of $34.5 \%$ with respect to considering only the horizontal component.

These values are also summarized in Table 3. Figure 12 shows plastic hinges for SCRU seismic register which are colored in red.

Table 3. Rotations generated by horizontal earthquake components and by horizontal and vertical earthquake components acting together (10-story building).

\begin{tabular}{cccccccc}
\hline \multirow{2}{*}{$\begin{array}{c}\text { Rotation } \\
\text { Computed }\end{array}$} & \multicolumn{7}{c}{ Rotation Values for Earthquake Station Register Considered (rad) } \\
\cline { 2 - 8 } & NILT & CALE & JAMI & SCRU & LANE & HMTT & RABO \\
\hline \multirow{2}{*}{$\theta_{h}$} & 0.0274 & 0.0107 & 0.0114 & 0.0175 & 0.0130 & 0.0100 & 0.0095 \\
\multirow{2}{*}{$\theta_{h+v}$} & $(2.41 \theta \mathrm{y})$ & $(0.94 \theta \mathrm{y})$ & $(1.0 \theta \mathrm{y})$ & $(1.54 \theta \mathrm{y})$ & $(1.14 \theta \mathrm{y})$ & $(0.88 \theta \mathrm{y})$ & $(0.84 \theta \mathrm{y})$ \\
& 0.0377 & 0.0330 & 0.0132 & 0.0276 & 0.0178 & 0.0137 & 0.0129 \\
& $(3.31 \theta \mathrm{y})$ & $(2.89 \theta \mathrm{y})$ & $(1.15 \theta \mathrm{y})$ & $(2.42 \theta \mathrm{y})$ & $(1.56 \theta \mathrm{y})$ & $(1.20 \theta \mathrm{y})$ & $(1.13 \theta \mathrm{y})$ \\
\hline
\end{tabular}




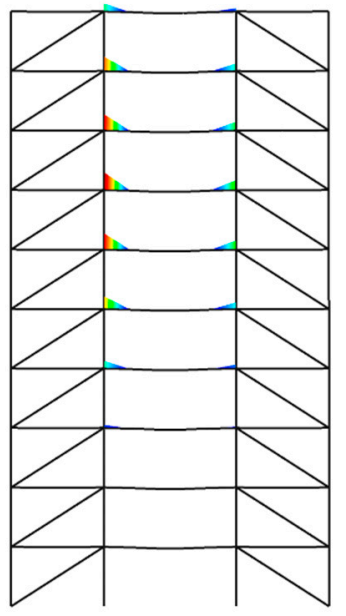

(a) Only horizontal component

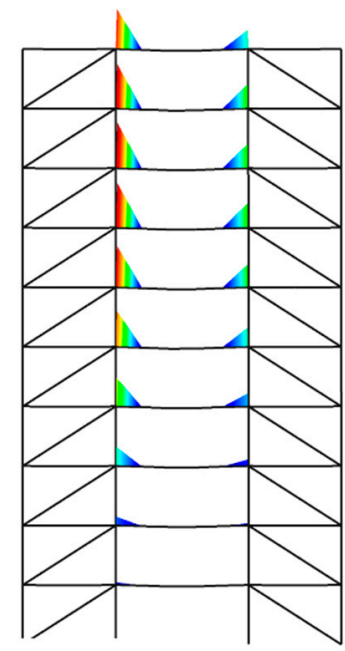

(b) Horizontal and vertical component

Figure 12. Plastic hinges for earthquake SCRU at the end of the seismic register. The red/blue color in the color contours indicates higher/lower degree of plastic rotation.

\section{Trends of Damage as a Function of Seismic Intensity}

In this section, it is investigated whether the level of a seismic intensity measure (IM) can be associated with the level of damage (in terms of rotation) of the steel beams for the considered hypothetical buildings. The pseudo-spectral acceleration, $\mathrm{Sa}$, is selected to inspect possible correlations with the beams rotations, because this IM is readily available in engineering practice and easier to communicate to decision makers.

First, the horizontal accelerations for the three vibration modes leading to the highest mass participation factors $\Gamma_{h}$ are obtained. This information is listed in Table 4 for the 6story building. It is pointed out that not necessarily the three first modes lead to the highest participation factors; whereas this is usually the case for the horizontal component, it is not for the vertical component. Then the square root of the sum of the squares (SRSS) of the horizontal accelerations is computed (denoted as $\mathrm{Sa} \mathrm{H}_{\text {SRSS }}$ ) with the following expression:

$$
\text { Sa } H_{\text {SRSS }}=\sqrt{\sum_{j=1}^{n} \frac{1}{n}\left[\Gamma_{h j} \times S a\left(T h_{j}\right)\right]^{2}}
$$

where $\mathrm{n}$ is the number of modes selected (i.e., 3 in this study), $\Gamma_{h j}$ is the mass horizontal modal participation factor for the $j$ mode and $S a\left(T h_{j}\right)$ is the pseudospectral acceleration for $j$ mode. Results are shown in Table 4.

Table 4. Accelerations due to horizontal earthquake in the 6-story building.

\begin{tabular}{|c|c|c|c|c|c|c|c|c|}
\hline \multirow{2}{*}{$\begin{array}{c}\text { Period } \\
\text { (s) }\end{array}$} & \multirow{2}{*}{${ }^{1} \Gamma_{h j}$} & \multicolumn{7}{|c|}{ Pseudospectral Horizontal Acceleration } \\
\hline & & ${ }^{2}$ Sa-NILT & ${ }^{2}$ Sa-CALE & ${ }^{2}$ Sa-JAMI & ${ }^{2}$ Sa-SCRU & ${ }^{2}$ Sa-LANE & ${ }^{2}$ Sa-HMTT & ${ }^{2}$ Sa-RABO \\
\hline 0.398 & 0.698 & 0.665 & 0.599 & 0.261 & 0.296 & 0.412 & 0.265 & 0.174 \\
\hline 0.108 & 0.196 & 1.864 & 1.059 & 0.613 & 0.532 & 0.548 & 0.348 & 0.309 \\
\hline 0.052 & $\begin{array}{c}0.043 \\
\Sigma \Gamma_{h}=0.937\end{array}$ & 1.232 & 0.563 & 0.909 & 0.405 & 0.457 & 0.213 & 0.233 \\
\hline Sa $H_{S R S S}$ & & 0.342 & 0.270 & 0.128 & 0.134 & 0.177 & 0.114 & 0.078 \\
\hline
\end{tabular}

${ }^{1} \Gamma_{h j}$ stands for mass horizontal modal participation factor; ${ }^{2} S a$ denotes the pseudospectral accelerations obtained for each spectrum (i.e., NILT, CALE, etc.) in the horizontal direction. 
Likewise, for the vertical accelerations with the highest modal participation (not necessarily the first three as mentioned before) $S a V_{S R S S}$ is computed with:

$$
S a V_{S R S S}=\sqrt{\sum_{j=1}^{n} \frac{1}{n}\left[\Gamma_{v j} \times S a\left(T v_{j}\right)\right]^{2}}
$$

where $\Gamma_{v j}$ stands for the mass vertical modal participation factor for the vertical direction and $S a\left(T v_{j}\right)$ denotes the pseudospectral accelerations obtained for each spectrum (i.e., NILT, CALE, etc.) in the vertical direction. The values are listed in Table 5.

Table 5. Accelerations due to horizontal earthquake in the 6-story building.

\begin{tabular}{|c|c|c|c|c|c|c|c|c|}
\hline \multirow{2}{*}{$\begin{array}{c}\text { Period } \\
\text { (s) }\end{array}$} & \multirow{2}{*}{${ }^{2} \boldsymbol{\Gamma}_{v j}$} & \multicolumn{7}{|c|}{ Pseudospectral Vertical Acceleration } \\
\hline & & ${ }^{2}$ Sa-NILT & ${ }^{2}$ Sa-CALE & ${ }^{2}$ Sa-JAMI & ${ }^{2}$ Sa-SCRU & ${ }^{2}$ Sa-LANE & ${ }^{2}$ Sa-HMTT & ${ }^{2}$ Sa-RABO \\
\hline 0.173 & 0.524 & 0.374 & 0.502 & 0.240 & 0.431 & 0.325 & 0.223 & 0.318 \\
\hline 0.164 & 0.046 & 0.432 & 0.495 & 0.247 & 0.493 & 0.353 & 0.231 & 0.278 \\
\hline 0.060 & 0.106 & 1.025 & 1.266 & 1.150 & 0.697 & 0.615 & 0.128 & 0.185 \\
\hline$S a V_{S R S S}$ & $\Sigma \Gamma_{v}=0.677$ & 0.130 & 0.171 & 0.101 & 0.138 & 0.105 & 0.068 & 0.097 \\
\hline
\end{tabular}

${ }^{2} \Gamma_{v j}$ stands for mass horizontal modal participation factor; ${ }^{2} S a$ denotes the pseudospectral accelerations obtained for each spectrum (i.e., NILT, CALE, etc.) in the vertical direction

To inspect which earthquake ground motion causes more damage when its horizontal and vertical components are simultaneously applied to the 6-story building, the information from Tables 4 and 5 is also included in Table 6 . Table 6 contains a new value termed as $A F$ (adjustment factor) that is calculated as the inverse of the sum of the modal participations $\Sigma \Gamma_{h}$ and $\Sigma \Gamma_{v}$, for the modes included in Tables 4 and 5, respectively; these are the inverse of 0.937 and 0.677 , leading to 1.066 and 1.477 , respectively. Then, $S a_{H \& V}$ is computed with:

$$
S a_{H \& V}=\sqrt{\frac{\left(\left(\Sigma \Gamma_{h}\right)^{-1} \times\left(S a H_{S R S S}\right)\right)^{2}+\left(\left(\Sigma \Gamma_{v}\right)^{-1} \times\left(S a V_{S R S S}\right)\right)^{2}}{2}}
$$

which is used to complete the values listed in Table 6.

Table 6. Resultant accelerations of the horizontal plus vertical components (6-story building).

\begin{tabular}{ccccccccc}
\hline Component & $\boldsymbol{A F}$ & Sa-NILT & Sa-CALE & Sa-JAMI & Sa-SCRU & Sa-LANE & Sa-HMTT & Sa-RABO \\
\hline$S a H_{S R S S}$ & 1.066 & 0.342 & 0.270 & 0.128 & 0.134 & 0.177 & 0.114 & 0.078 \\
$S a V_{S R S S}$ & 1.477 & 0.130 & 0.171 & 0.101 & 0.138 & 0.105 & 0.068 & 0.097 \\
$S a_{H \& V}$ & & 0.292 & 0.271 & 0.1438 & 0.176 & 0.173 & 0.111 & 0.117 \\
\hline
\end{tabular}

The values in Table 6 and the corresponding rotations from the non-linear analyses are depicted in Figure 13 (blue points) for the beams reported in Figures 7 and 8. Additionally, in Figure 13 simple linear fits are shown to visualize possible trends. In general, Figure 13 shows that larger damage (rotation) is expected for larger horizontal Sa (Figure 13 left) and that, the same occurs, but with even higher damage when the horizontal and vertical components act simultaneously (Figure 13 right). In both cases the plastic rotation is 0.0109 .

Analogous results and trends are listed in Tables 7-9 and Figure 14. The same conclusions can be drawn, except that the dispersion of the damage around the trend line is higher for the 10-story building under the action of both components (Figure 14 right). Results for other beams are not shown for brevity, but they exhibit similar trends but with a value of plastic rotation equal to 0.0114 . 
Table 7. Accelerations due to horizontal earthquake in the 10-story building.

\begin{tabular}{|c|c|c|c|c|c|c|c|c|}
\hline \multirow{2}{*}{$\begin{array}{c}\text { Periodo } \\
\text { (s) }\end{array}$} & \multirow{2}{*}{$\Gamma_{h j}$} & \multicolumn{7}{|c|}{ Pseudospectral Horizontal Acceleration } \\
\hline & & Sa-NILT & Sa-CALE & Sa-JAMI & Sa-SCRU & Sa-LANE & Sa-HMTT & Sa-RABO \\
\hline 0.8412 & 0.738 & 0.379 & 0.229 & 0.195 & 0.294 & 0.224 & 0.126 & 0.070 \\
\hline 0.2383 & 0.157 & 1.383 & 0.733 & 0.245 & 0.457 & 0.521 & 0.301 & 0.320 \\
\hline 0.1216 & 0.039 & 2.048 & 1.187 & 0.671 & 0.597 & 0.557 & 0.275 & 0.322 \\
\hline $\mathrm{Sa} \mathrm{H}_{S R S S}$ & $\Sigma \Gamma_{h}=0.934$ & 0.210 & 0.121 & 0.087 & 0.132 & 0.107 & 0.060 & 0.042 \\
\hline
\end{tabular}

Table 8. Accelerations due to vertical earthquake in the 10-story building.

\begin{tabular}{|c|c|c|c|c|c|c|c|c|}
\hline \multirow{2}{*}{$\begin{array}{l}\text { Periodo } \\
\text { (s) }\end{array}$} & \multirow{2}{*}{$\Gamma_{v j}$} & \multicolumn{7}{|c|}{ Pseudospectral Vertical Acceleration } \\
\hline & & Sa-NILT & Sa-CALE & Sa-JAMI & Sa-SCRU & Sa-LANE & Sa-HMTT & Sa-RABO \\
\hline 0.198 & 0.398 & 0.263 & 0.584 & 0.198 & 0.292 & 0.259 & 0.277 & 0.247 \\
\hline 0.122 & 0.070 & 0.766 & 0.587 & 0.366 & 0.464 & 0.494 & 0.172 & 0.216 \\
\hline 0.058 & 0.254 & 1.004 & 1.287 & 1.128 & 0.701 & 0.634 & 0.125 & 0.187 \\
\hline$S a V_{S R S S}$ & $\Sigma \Gamma_{v}=0.722$ & 0.162 & 0.233 & 0.172 & 0.124 & 0.112 & 0.066 & 0.063 \\
\hline
\end{tabular}

Table 9. Resultant accelerations of the horizontal plus vertical components (10-story building).

\begin{tabular}{ccccccccc}
\hline Component & $\boldsymbol{A F}$ & Sa-CALE & Sa-JAMI & Sa-LANE & Sa-HMTT & Sa-NILT & Sa-RABO & Sa-SCRU \\
\hline$S a H_{S R S S}$ & 1.070 & 0.121 & 0.087 & 0.107 & 0.060 & 0.210 & 0.042 & 0.132 \\
$S a V_{S R S S}$ & 1.383 & 0.233 & 0.172 & 0.112 & 0.066 & 0.162 & 0.063 & 0.124 \\
$S a_{H \& V}$ & & 0.245 & 0.181 & 0.136 & 0.080 & 0.224 & 0.070 & 0.157 \\
\hline
\end{tabular}
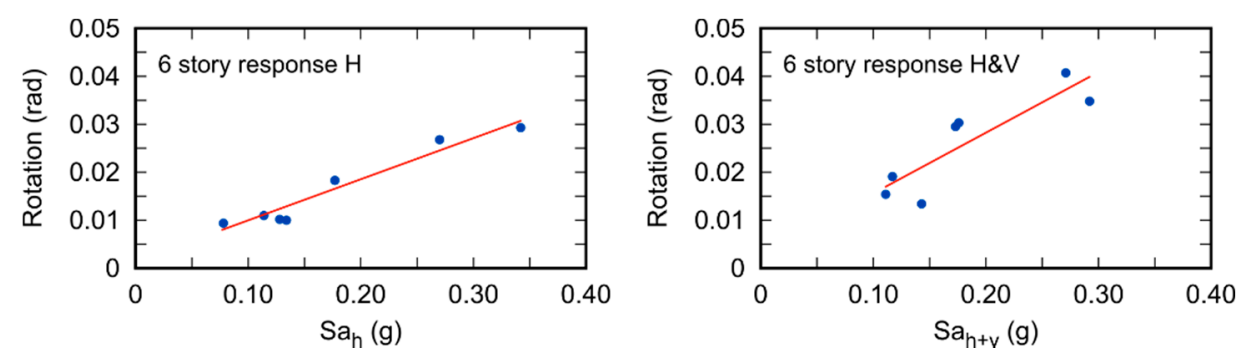

Figure 13. Rotation as a function of Sa for the 6-story building for beams studied in Figures 7 and 8; left for the horizontal component, right for the horizontal plus vertical component.
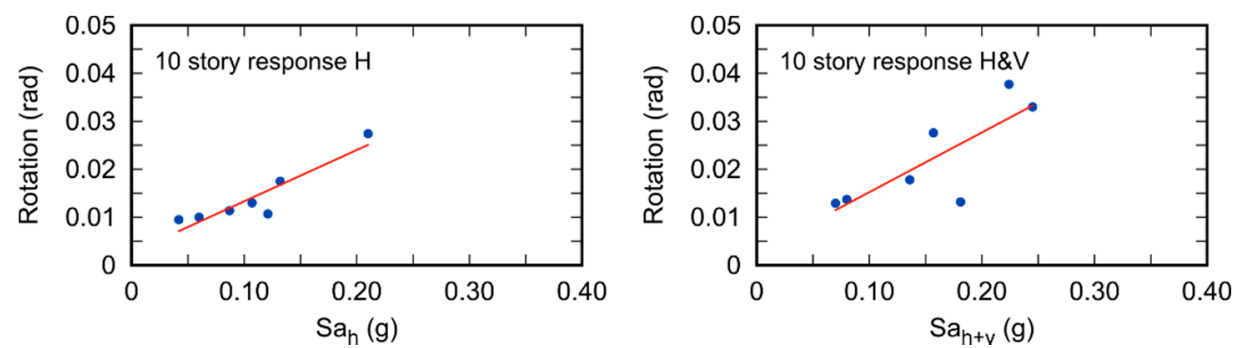

Figure 14. Rotation as a function of Sa for the 10-story building; for beams studied in Figures 10 and 11. Left for the horizontal component, right for the horizontal plus vertical component.

Before proceeding to the next section, it is emphasized that Equation (3) leads to the consistent (quantifiable) trend shown in Figure 13 because the modes with the highest modal participation (not necessarily the first three) are used and an extrapolation is carried out to consider the $100 \%$ mass participation. Other combinations of the response (different 
to Equation (3)) do not lead to this consistent trend. Therefore, Equation (3) is considered as a contribution of the present study.

\section{Performance Level of Critical Beams}

To discuss the performance level of the beams studied, guidelines from the American Society of Civil Engineering-ASCE SEI 41-17, [35] are considered. The stipulated criteria in that reference (acceptance criteria) are divided in: immediate occupancy (IO), life safety (LS) and collapse prevention (CP).

If the beams in the examples presented above, and the reference values $\mathrm{IO}=1 \theta \mathrm{y}$, $\mathrm{LS}=9 \theta \mathrm{y}$ and CP $=11 \theta \mathrm{y}$, are considered, it is noted that in no case the LS level is reached. However, it was noticed that if only the horizontal seismic component is considered, the elements remain in the elastic range in several cases, as for stations JAMI, SCRU and RABO for the 6-story building, and as for stations CALE, HMTT and RABO for the 10-story building.

As reported before, the rotations change, sometimes significantly, when both, the horizontal and the vertical, components are considered. In almost all cases there are increases in rotation ranging from $15 \%$ to up to about $207 \%$ for the two-component analysis as compared to the one-component non-linear dynamic analysis. This indicates that the response could lead to different acceptation criteria levels in the ASCE SEI 41-17, depending on whether both components are acting simultaneously.

Therefore, it is concluded that while a certain structure would reach the LS acceptation level with the horizontal component only, it could reach the $\mathrm{CP}$ acceptation level if both components are acting simultaneously. This is important, because it may imply that a supposedly rightly designed structure could collapse if the horizontal and vertical components act together. This is schematically illustrated for some cases in Figures 15 and 16 for the 6-story building, and Figures 17 and 18 for the 10-story building.

For instance, Figure 15 shows that for the case in the bottom-left column of the figure (case CALE-5S-LS) the rotation resulting from the horizontal component $(\mathrm{H})$ is located within the LS performance level, whereas the rotation caused by both components acting together $(\mathrm{H} \& \mathrm{~V})$ increases the rotation, but it is also within the LS performance level. This is also observed in Figure 15 in the top-left column of the figure (case NILT-7S-LS).
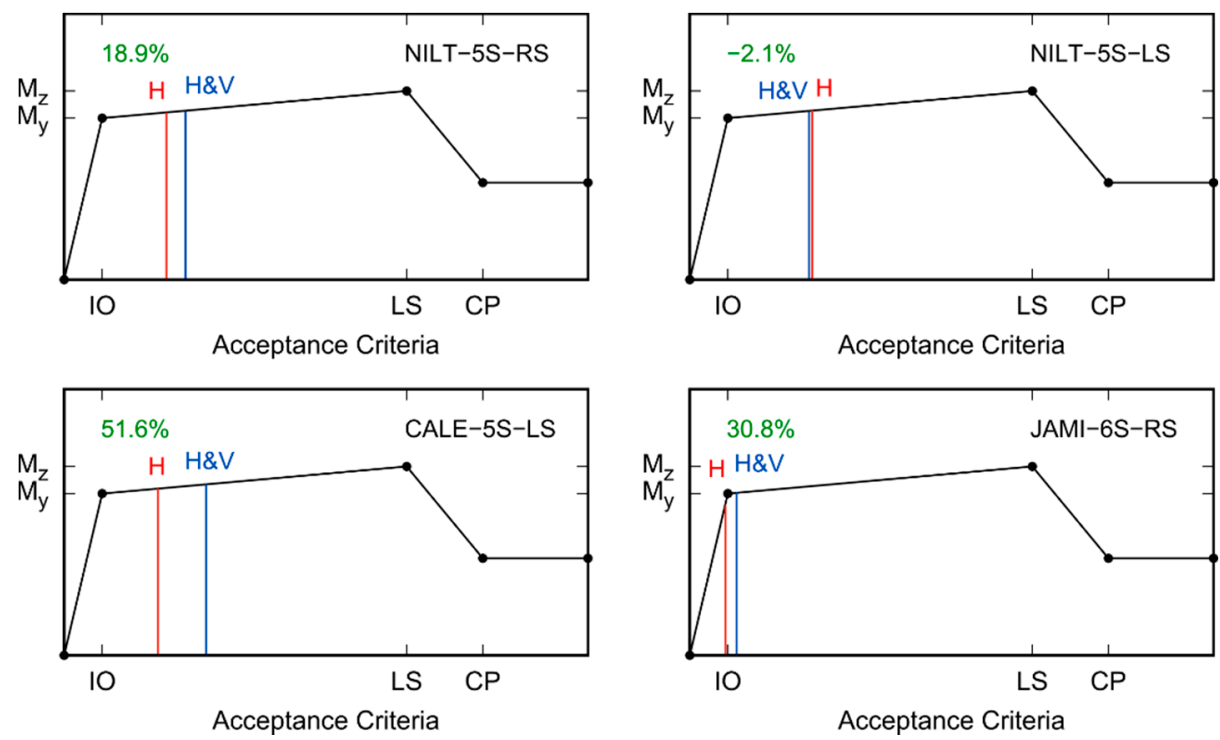

Figure 15. Examples of acceptance criteria for the 6-story building. Part 1.

Contrarily, the other cases in Figures 16 and 17 (cases SCRU-6S-RS and CALE-9S-LS, respectively) do lead to a change in the performance level from IO to LS when the vertical component is added in the analyses. These results indicate that inclusion of the effects of 
the vertical component of earthquake ground motion, when considered simultaneously with the horizontal component, can also have an impact in codified design. Therefore, code developers and designers should also be aware of this impact for practical purposes.

Figures 15 and 16 and Figures 17 and 18 shows the acceptance criteria of beams studied in Figures 7 and 8 and Figures 10 and 11, respectively. In all these figures, at the top-left of each individual figure the percentage difference between horizontal and horizontal + vertical acceptance criteria are shown in green.

It could be argued that the results in this section may not be useful in practice, because the structures considered in this section meet the strong-column weak-beam philosophy but are not realistically code-designed buildings. Therefore, a moment-resisting steel frame, designed by a practicing engineer to withstand seismic loads in accordance with an international code, is used in the following section to further inspect the obtained results, in terms of the seismic performance levels due to the adding effects of the vertical component.
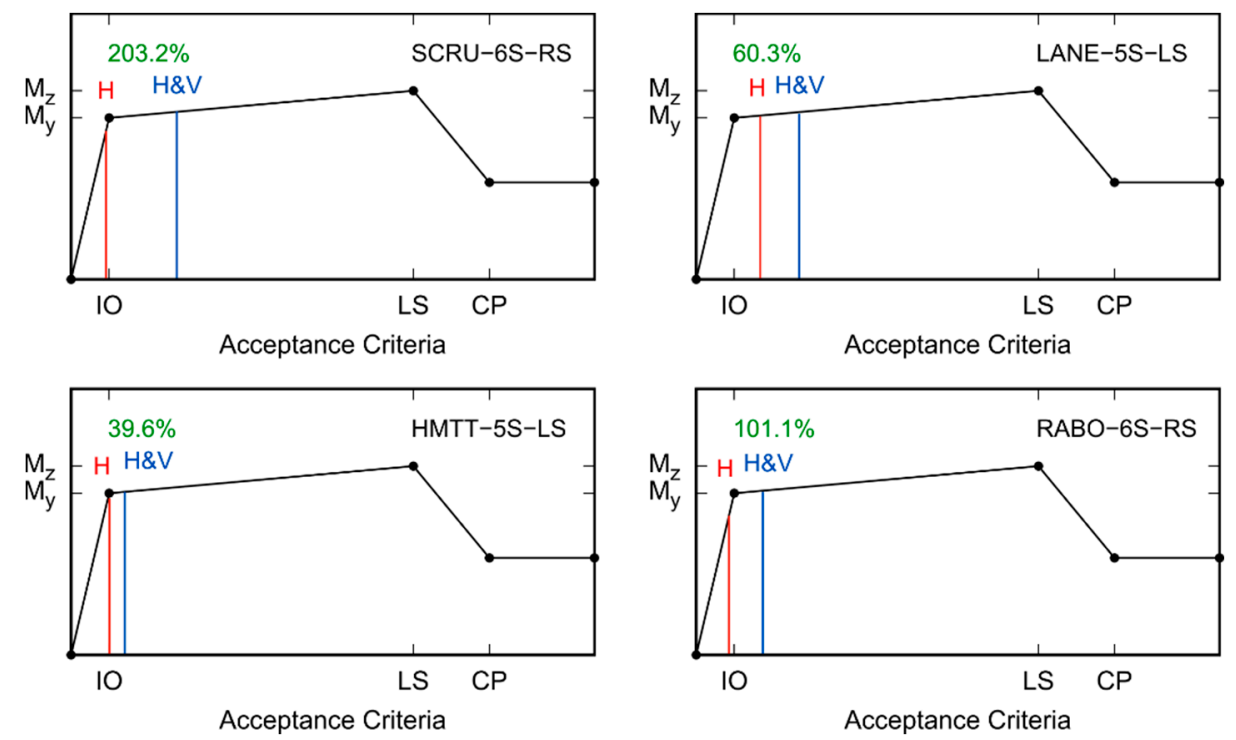

Figure 16. Examples of acceptance criteria for the 6-story building. Part 2.
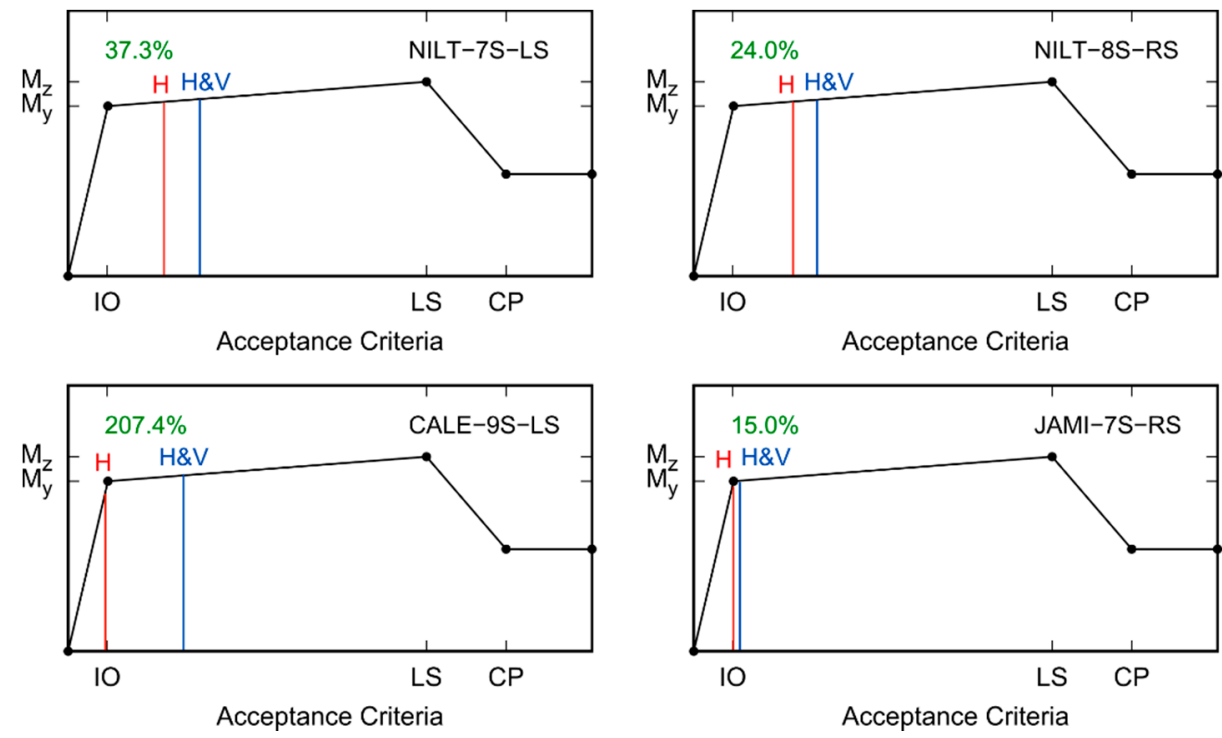

Figure 17. Examples of acceptance criteria for the 10-story building. Part 1. 

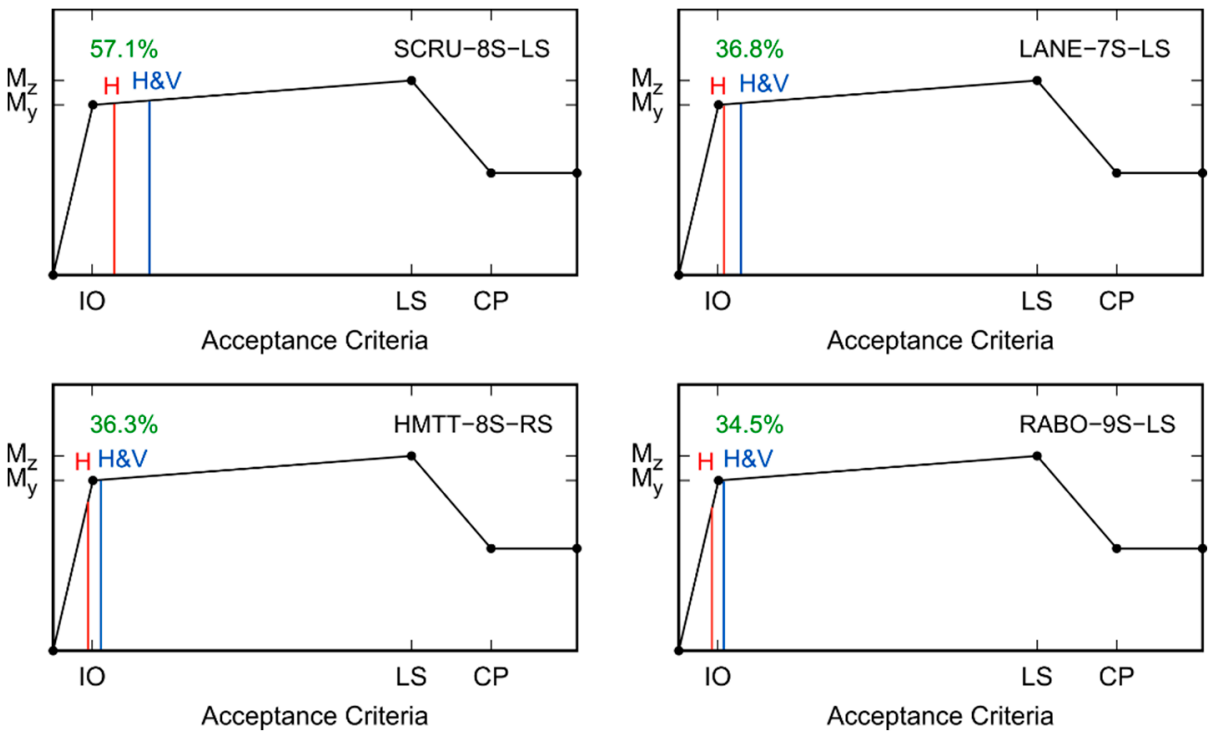

Figure 18. Examples of acceptance criteria for the 10-story building. Part 2.

\section{Performance Levels of a Code-Designed Structure}

In this section, the same procedure used to obtain the results shown in Figures 15-18 is applied to a structure designed by an experienced practicing engineer (Roeder et al., 1993 [36]; Schneider et al., 1993 [37]) as per the seismic provisions of the Uniform Building Code (UBC, 1988 [38]). This structure could be considered more representative of existing structures and be closer in design terms to buildings located in seismic-prone regions, in comparison to the structures considered in the previous sections.

It is the eight-story moment-resisting steel frame showed in Figure 19, where the WShapes of A-36 steel for beams and columns can be observed, together with the dimensions and the points with the largest rotations (red dots); depicted green symbols indicate change in the columns section (at midstory).

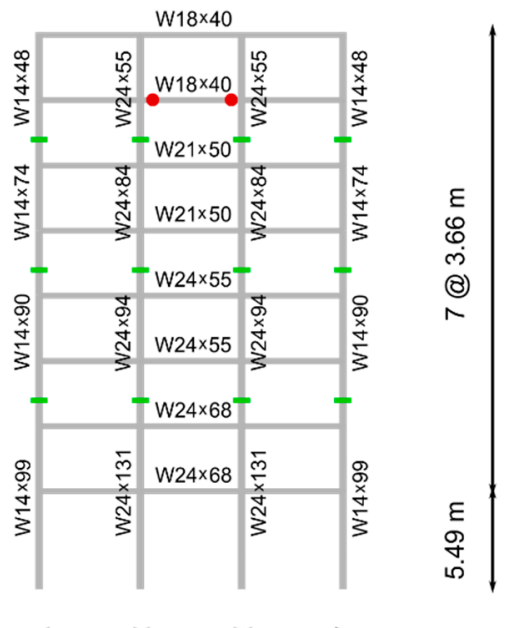

$7.31 \mathrm{~m} \quad 7.31 \mathrm{~m} \quad 7.31 \mathrm{~m}$

Figure 19. Realistic code-designed moment-resisting steel frame to assess seismic performance levels. Red dots denote selected plastic hinges. Green symbols indicate the section change at midstory.

This structure just meets the UBC (1988) [38] requirements for earthquake design (Roeder et al., 1993 [36]; Schneider et al., 1993 [37]). The considered gravity load (including dead load and live load) in the non-linear analyses is $52.54 \mathrm{kN} / \mathrm{m}$ at interstory levels and $43.78 \mathrm{kN} / \mathrm{m}$ at roof level. The self-weight of the elements is considered in the analyses. 
These uniformly distributed loads are based on the loads per area unit reported for this structure (Roeder et al., 1993 [36]; Schneider et al., 1993 [37]) and the consideration that the frame corresponds to a central frame and that the tributary areas for each side of the beams are half of the area for a given floor.

For the eight-story building, the first horizontal vibration period is $\mathrm{T}_{1 \mathrm{~h}}=2.048 \mathrm{~s}$, the second is $\mathrm{T}_{2 \mathrm{~h}}=0.738 \mathrm{~s}$ and the third one is $\mathrm{T}_{3 \mathrm{~h}}=0.415 \mathrm{~s}$. The same corresponding periods, but for the vertical response are $\mathrm{T}_{1 \mathrm{v}}=0.230 \mathrm{~s}, \mathrm{~T}_{2 \mathrm{v}}=0.151 \mathrm{~s}$ and $\mathrm{T}_{3 \mathrm{v}}=0.126 \mathrm{~s}$, respectively.

Roeder et al., 1993 [36] reported only the fundamental period for the horizontal component. Some assumptions were made with the available information found in [36], as mentioned above. This led to some variation in the fundamental period since a period of $2.4 \mathrm{~s}$ is indicated in [36].

The structure in Figure 19 is to be subjected to the records in Table 1 for the non-linear dynamic analyses too, plus other four Mexican records listed in Table 10. The corresponding response spectra are depicted in Figure 20 for the additional records.

Table 10. Additional Mexican ground motions used in this section.

\begin{tabular}{cccccccccc}
\hline Station & Direction & Date & $\begin{array}{c}\text { Magnitud } \\
\mathbf{M w}\end{array}$ & $\begin{array}{c}\text { Rrup } \\
\mathbf{( k m )}\end{array}$ & Lat. & Long. & H (km) & $\begin{array}{c}\text { PGA }_{\mathbf{h}} \\
\mathbf{( g )}\end{array}$ & $\begin{array}{c}\text { PGA }_{\mathbf{v}} \\
(\mathbf{g})\end{array}$ \\
\hline BALC & EW & $1994 / 12 / 10$ & 6.4 & 59.2 & 17.98 & 101.52 & 50 & 0.185 \\
PANG & EW & $1999 / 09 / 30$ & 7.4 & 50.0 & 16.03 & 96.96 & 47 & 0.114 \\
PETA & EW & $1994 / 12 / 10$ & 6.4 & 74.8 & 17.98 & 101.52 & 50 & 0.208 \\
RIOG & EW & $1999 / 09 / 30$ & 7.4 & 33.8 & 16.03 & 96.96 & 47 & 0.303 & 0.096 \\
\hline
\end{tabular}
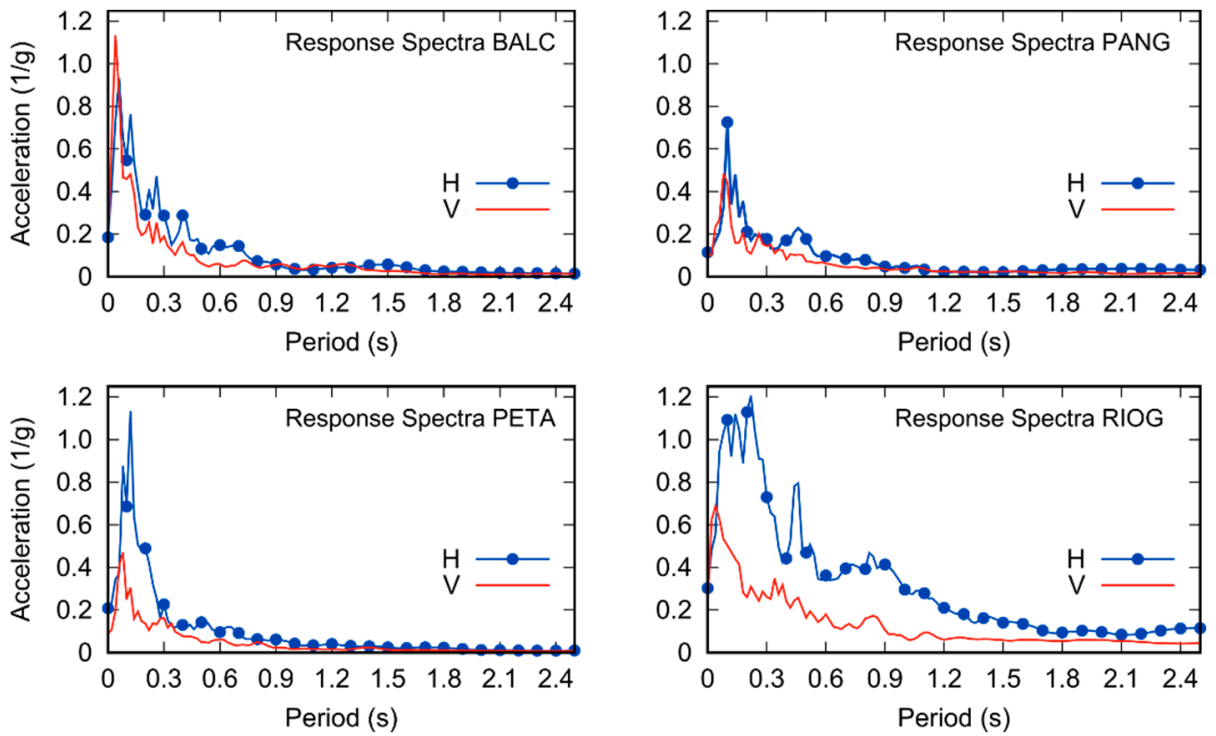

Figure 20. Response spectra for the ground motions in Table 10.

The non-linear response is computed as before, i.e., the OpenSEES program [32], the pre- and post-processor GiD [33] and the coupling interface GiD+OpenSees Platform [34] are used with the same previously stated assumptions and nomenclature, except that the steel frame in Figure 19 and its characteristics are considered. Distributed plasticity with fibers in all the elements is assumed. However, in this case, the P-delta effect is not added for simplicity and at intersections the joint offset node was not taken into account.

The results are shown in Figures 21-23 for the red dots in Figure 19. The W18 $\times 40$ beams on the 7th floor have a yielding flexure moment $\mathrm{My}=278.1 \mathrm{kN}-\mathrm{m}$ and a yielding rotation $\theta y=0.0076 \mathrm{rad}$. It is observed that the beam undergoes into the inelastic range for almost the 11 ground motions (except for the PETA-7S-LS case) and that, when both 
components act simultaneously, larger plastic rotations (from moderate to significant increases) are obtained.
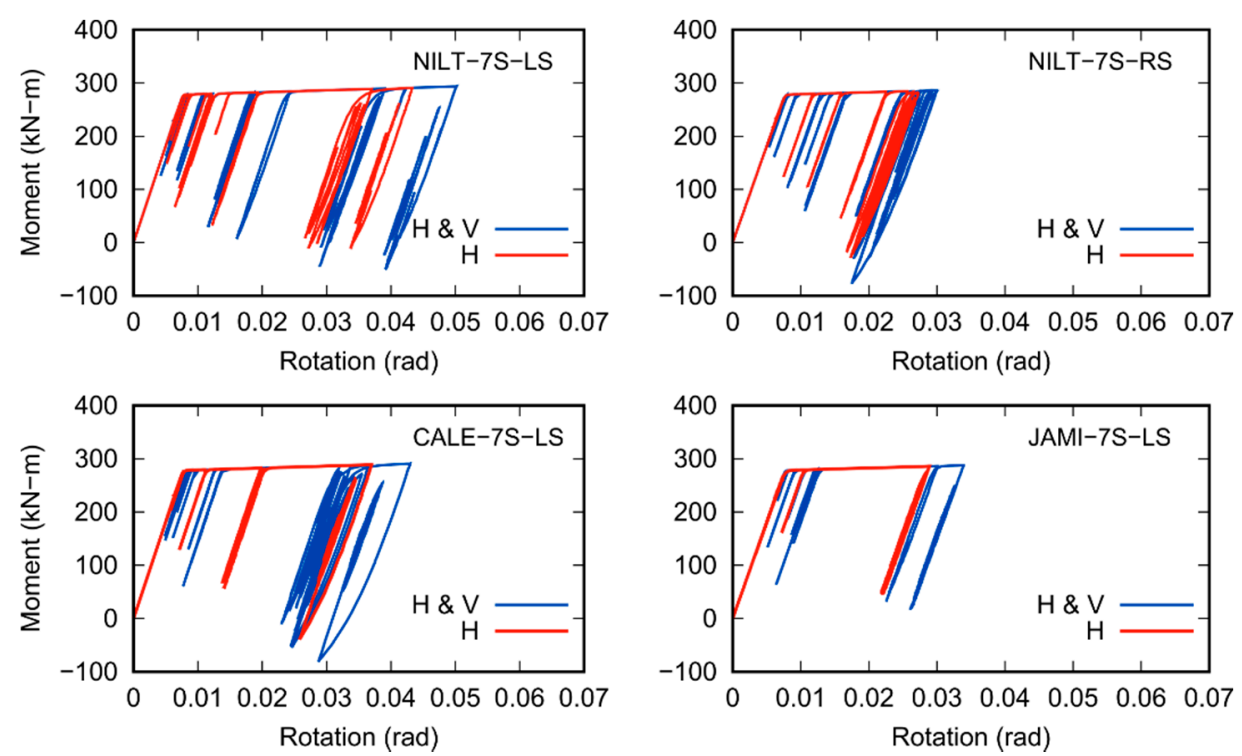

Figure 21. Non-linear response of the outer-most fiber in the considered beam for different earthquakes; 8-story building (Part 1).
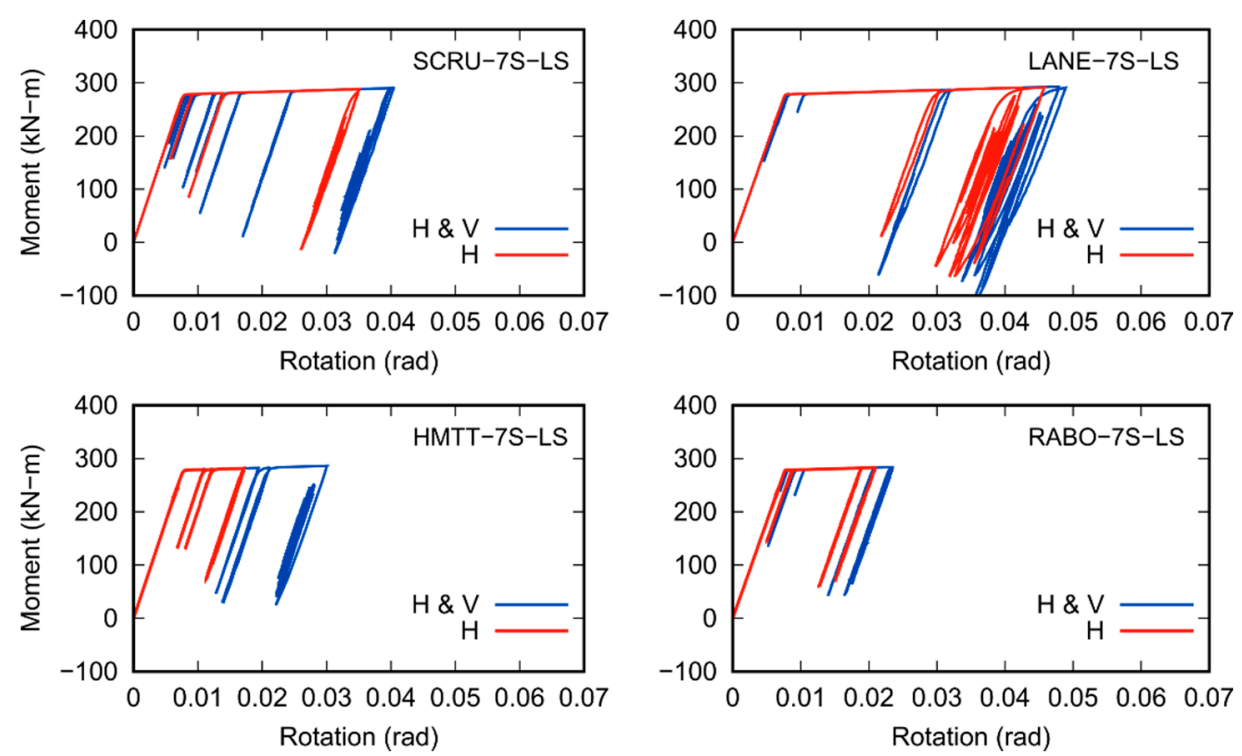

Figure 22. Non-linear response of the outer-most fiber in the considered beam for different earthquakes; 8-story building (Part 2).

These results confirmed the findings in the previous section, namely, the inclusion of the vertical component in the analyses can lead to significant larger plastic rotations. This also implies that the structure could change its performance level if the vertical component of the ground motion is considered together with the horizontal component. This is to be discussed shortly after.

The acceptance criteria for the steel frame in Figure 19 are shown in Figures 24-26. Again, the considered acceptance thresholds in this last example have values $\mathrm{IO}=1 \theta \mathrm{y}$, $\mathrm{LS}=9 \theta \mathrm{y}$ and $\mathrm{CP}=11 \theta \mathrm{y}$. As for the previous examples, in Figures 24-26 the increasing effect due to the addition of the seismic vertical component is readily observed and, although the crossing of a threshold (in terms of the acceptance criteria) is not as clearly observed, 
case BALC-7S-LS can be seen as an example that including the simultaneous occurrence of the vertical component in the analysis may lead to a change from IO to LS. The increase in terms of percentage can be also significant as observed for instance for case HMTT-7S-LS in Figure 25 (as before, percentages are indicated in green in the left upper corner for each case). It is highlighted that the largest rotations of $0.0502 \mathrm{rad}$ and $0.0489 \mathrm{rad}$ are obtained for cases NILT-7S-Ls and LANE-7S-LS, respectively.
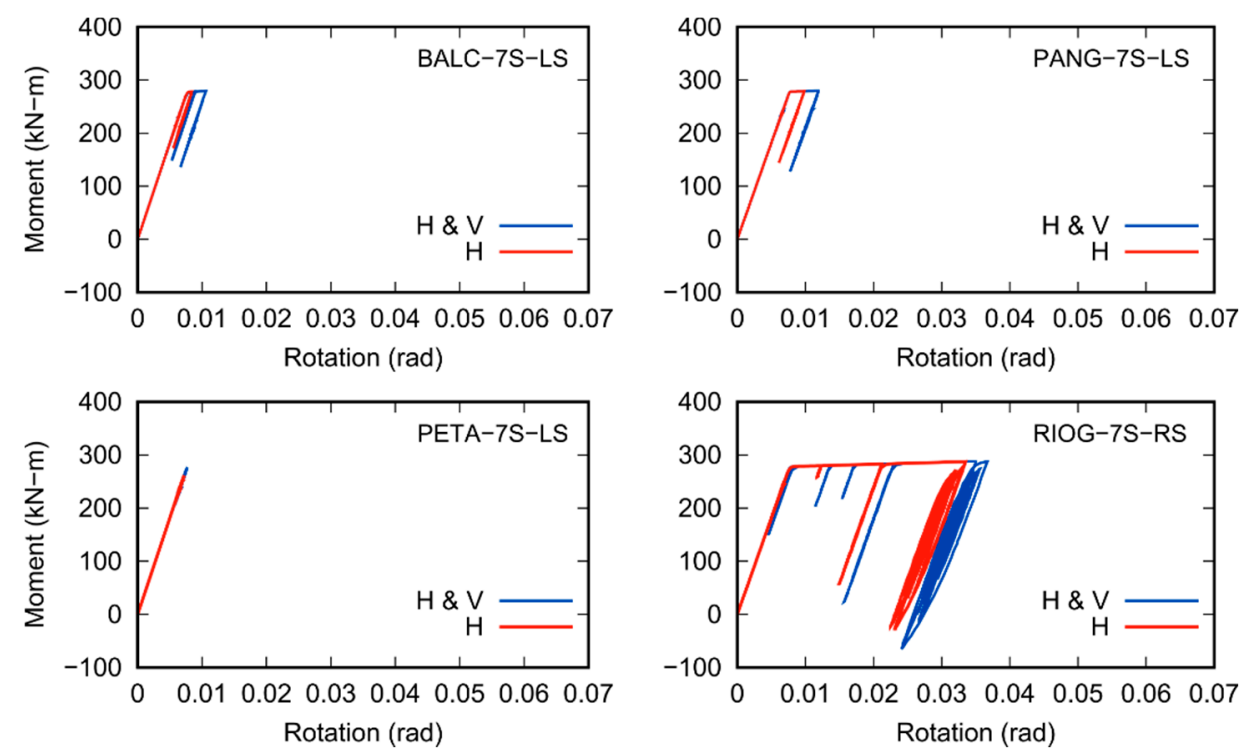

Figure 23. Non-linear response of the outer-most fiber in the considered beam for different earthquakes; 8-story building (Part 3).
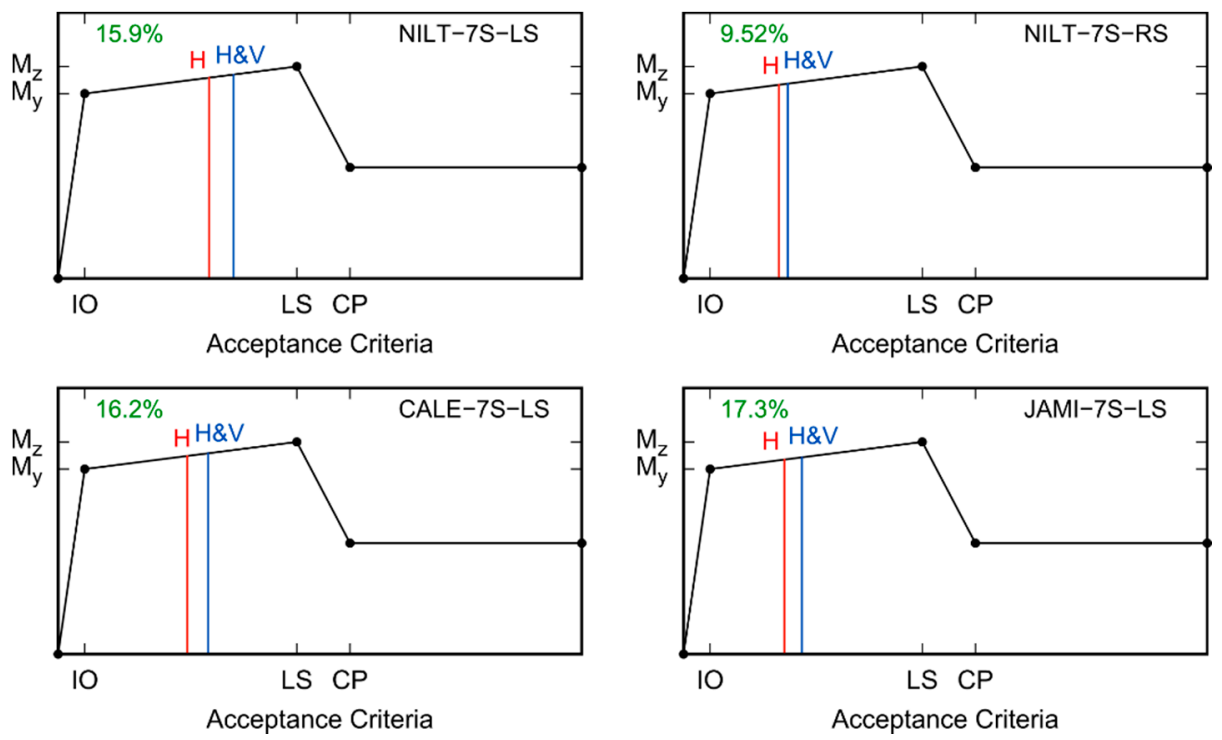

Figure 24. Examples of acceptance criteria for the 8-story building. Part 1. 

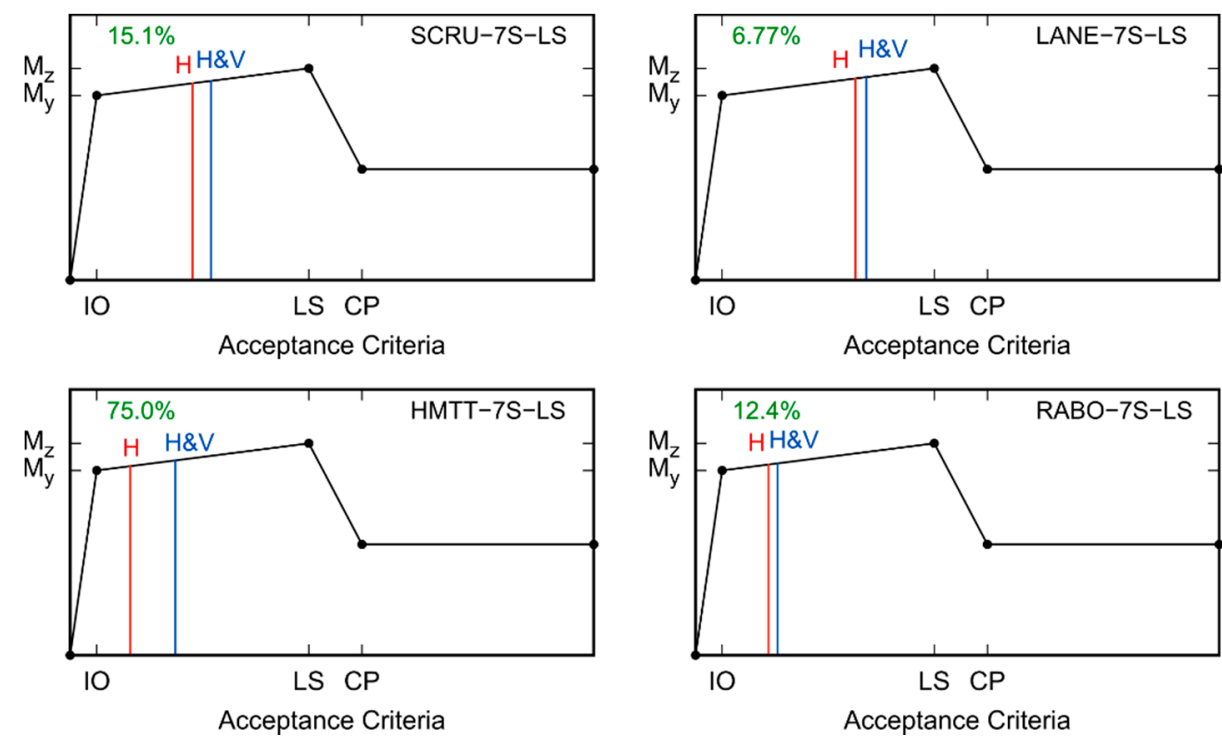

Figure 25. Examples of acceptance criteria for the 8-story building. Part 2.
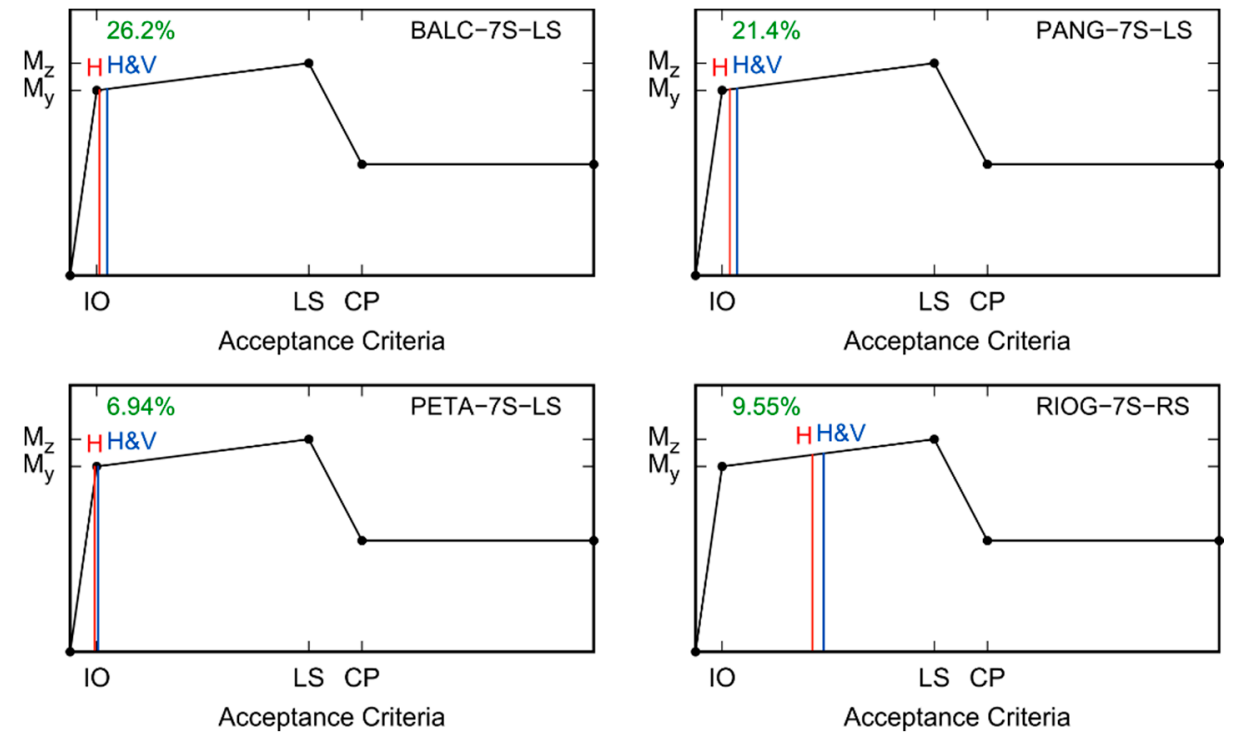

Figure 26. Examples of acceptance criteria for the 8-story building. Part 3.

In Table 11, a summary of the maximum rotations for all considered records is given.

Table 11. Rotations generated by horizontal earthquake components and by horizontal and vertical earthquake components acting together (8-story building).

\begin{tabular}{cccccccccccc}
\hline \multirow{2}{*}{$\begin{array}{c}\text { Rotation } \\
\text { Computed }\end{array}$} & \multicolumn{8}{c}{ Rotation Values for Earthquake Station Register Considered (rad) } \\
\cline { 2 - 12 } & NILT & CALE & JAMI & SCRU & LANE & HMTT & RABO & BALC & PANG & PETA & RIOG \\
\hline \multirow{2}{*}{$\theta_{h}$} & 0.0433 & 0.0370 & 0.0289 & 0.0351 & 0.0458 & 0.0172 & 0.0209 & 0.0084 & 0.0098 & 0.0072 & 0.0335 \\
& $(5.7 \theta \mathrm{y})$ & $(4.9 \theta \mathrm{y})$ & $(3.8 \theta \mathrm{y})$ & $(4.6 \theta \mathrm{y})$ & $(6.0 \theta \mathrm{y})$ & $(2.3 \theta \mathrm{y})$ & $(2.8 \theta \mathrm{y})$ & $(1.1 \theta \mathrm{y})$ & $(1.3 \theta \mathrm{y})$ & $(0.95 \theta \mathrm{y})$ & $(4.4 \theta \mathrm{y})$ \\
$\theta_{h+v}$ & 0.0502 & 0.0430 & 0.0339 & 0.0404 & 0.0489 & 0.0301 & 0.0235 & 0.0106 & 0.0119 & 0.0077 & 0.0367 \\
& $(6.6 \theta \mathrm{y})$ & $(5.7 \theta \mathrm{y})$ & $(4.5 \theta \mathrm{y})$ & $(5.3 \theta \mathrm{y})$ & $(6.4 \theta \mathrm{y})$ & $(4.0 \theta \mathrm{y})$ & $(3.1 \theta \mathrm{y})$ & $(1.4 \theta \mathrm{y})$ & $(1.6 \theta \mathrm{y})$ & $(1.01 \theta \mathrm{y})$ & $(4.8 \theta \mathrm{y})$ \\
\hline
\end{tabular}

Therefore, the structural response of the moment-resisting steel frame in Figure 19 under the seismic records in Tables 1 and 10 demonstrates that the conclusions previously stated (for the frames in Figure 1) hold also for a realistic code-designed structure subjected to real ground motions. It is, therefore, considered that the findings in this study can be of 
guidance for practical applications and can further highlight that the simultaneous action of the vertical component and the horizontal component (as it occurs in the real physical phenomenon) should not be disregarded in seismic design. It is acknowledged though, that the study is far from exhaustive and that further research using different steel structures configurations, standards and ground motions is required.

One last figure, Figure 27, is analogous to Figures 13 and 14, but considering the codedesigned steel frame in this section. It can be observed that the increasing trends of rotations as a function of increasing Sa is also confirmed (with some more dispersion though). Notice that the pseudo-accelerations are not so large for the horizontal component alone. The reason is that the structural periods correspond to small spectral ordinates. However, when both components are considered, the spectral ordinates for the vertical component corresponds to larger spectral ordinates, shifting this case to larger Sa in Figure 27. In contrast, the difference in terms of rotations is not as noticeable for both cases depicted in Figure 27.
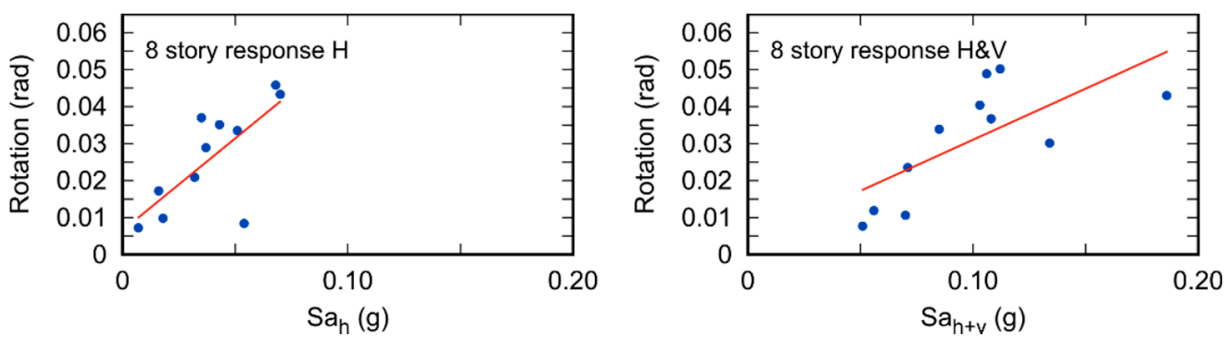

Figure 27. Rotation as a function of Sa for the 8-story building beam (see Figure 19). Left for the horizontal component, right for the horizontal plus vertical component.

\section{Discussion}

This study discusses the impact of the vertical earthquake ground motion component in the performance level of steel building beams. First, two hypothetical steel-frame buildings with diagonals are used as case studies to perform seismic non-linear dynamic analyses subjected to earthquake excitations from very large earthquakes that damaged many structures in Mexico. OpenSEES software is used to inspect the performance of the steel beams in terms of plastic rotations. The performance is inspected from the perspective of codified design.

It was found that the inclusion of the vertical component of earthquake ground motion, located near the causative fault, in the analysis leads to larger plastic rotations in the beams (i.e., when both, the horizontal and vertical components act simultaneously on the structure), compared to the rotations obtained by subjecting the structure to the earthquake excitations of only the horizontal component.

It had not been previously reported that most of the practical cases focus only on the horizontal component, and when the vertical component is included it does not significantly change the load effects, as described in [7]. An important change in the load effects of the structural elements is obtained when considering consistent mass matrices in the analysis, which is not common to find in commercial software [7]. Another way to achieve this change is through the discretization of the structural elements as is done with the analyses based on the finite element method.

It is concluded that designers and code developers should incorporate as criterion to perform non-linear analyses of the horizontal and vertical components acting together, because this leads in some elements to a change in the acceptation criteria in codified design to a most critical one when both components act simultaneously. This would be particularly important for places where the vertical component becomes relevant (near the source). General trends indicate that larger pseudo-spectral accelerations lead to larger plastic rotations of the steel beams. These general trends also confirm that structures subjected to the simultaneous action of horizontal and vertical components of ground motion yield 
larger plastic rotations (as compared to those from the one-component analysis) for the same level of pseudo-spectral acceleration.

Moreover, a more realistic structure was also considered to validate the results. It was demonstrated that when a steel frame designed by a practicing engineer is subjected to real near-fault ground motions by means of non-linear analyses, the same conclusions hold. It is acknowledged that other seismic standards, including the newest versions of worldwide used codes, more recordings representative of the seismic hazard of a given structure designed as per the applicable regulations, other structural typologies, and other materials (e.g., reinforced concrete frames) should be considered to have further insight into the findings of the present study. This is recommended for further research.

\section{Conclusions}

Current structural design regulations for the construction of buildings in seismic zones specify that a non-linear seismic analysis could be performed. Depending on the type of structure, it can be a non-linear static seismic analysis (pushover) or a non-linear dynamic seismic analysis. An important difference between both methods is that generally different acceptance levels result for the same structure, becoming more critical when performing a dynamic seismic analysis.

Taking this into account, in this work a non-linear dynamic seismic analysis was carried out where both the horizontal component and the vertical component of several seismic records occurred in Mexico are considered. Two hypothetical and one realistic (code-designed) steel frames are considered.

It was found that the dynamic analysis considering the horizontal and the vertical components simultaneously (as compared to using only the horizontal component), does not always lead to the largest rotation. This does not occur in most cases and could be attributed to the counteracting effect of the vertical component for certain ground motions and considered structure.

In addition, it is found that there are higher levels of acceptance (i.e., larger plastic rotations) when both seismic components (horizontal and vertical acting simultaneously) are considered than when only the horizontal component is considered, as happens in most practical cases. It is recommended to include the vertical seismic component in future earthquake assessment and design of buildings since the extra calculation effort is minimal (compared to a dynamic analysis by considering only the horizontal component).

This study contributes to the understanding of structural behavior by considering the effect of both components of ground motions from a specific tectonic environment, since Mexican earthquakes are used.

A simple quantitative expression to correlate the non-linear response (in terms of plastic rotations) and a ground motion intensity measure (pseudo-spectral acceleration) is proposed. In the proposed equation the three modes with the highest modal participation, which are not necessarily the first three, are used. Since other combinations of the response do not lead to this consistent trend, the proposed expression is considered as a contribution of the present study.

It is acknowledged that in order to formulate more robust conclusions, further studies are required by extending the analysis to other structures and by using many other recorded near-fault ground motions, while also incorporating more refined modelling assumptions for the elements and connections of realistic structures.

Other aspects which are recommended for further research are to explore a probabilistic rather than a deterministic approach (for instance to obtain median values of the response using two components, while also determining the variability in quantitative terms), as well as the use of scaled records to guarantee that many members of realistic structures undergo into the inelastic range consistent with future extraordinary seismic scenarios. 
Author Contributions: Conceptualization, J.-G.V.-V., A.D.G.-S. and M.Á.J.; methodology, J.-G.V.-V., A.D.G.-S. and M.Á.J.; software, J.-G.V.-V., A.D.G.-S. and M.Á.J.; validation, J.-G.V.-V., A.D.G.-S. and M.Á.J.; formal analysis, J.-G.V.-V., A.D.G.-S. and M.Á.J.; investigation, J.-G.V.-V., A.D.G.-S. and M.Á.J.; resources, J.-G.V.-V., A.D.G.-S. and M.Á.J.; data curation, J.-G.V.-V., A.D.G.-S. and M.Á.J.; writingoriginal draft preparation, J.-G.V.-V., A.D.G.-S. and M.Á.J.; writing-review and editing, J.-G.V.-V., A.D.G.-S. and M.Á.J.; visualization, J.-G.V.-V., A.D.G.-S. and M.Á.J.; supervision, J.-G.V.-V., A.D.G.-S. and M.Á.J.; project administration, J.-G.V.-V. and A.D.G.-S.; funding acquisition, J.-G.V.-V. All authors have read and agreed to the published version of the manuscript.

Funding: The financial support from Universidad de Guanajuato (División de Ingenierías and Campus Guanajuato) is gratefully acknowledged.

Acknowledgments: We are grateful to the International Centre for Numerical Methods in Engineering (CIMNE) for providing us with the pre- and post-processor GiD (2020) in our CIMNE-classroom at the Civil Engineering Department. We are thankful to four anonymous reviewers for their comments, suggestions and constructive criticism, which helped to improve this study.

Conflicts of Interest: The authors declare no conflict of interest.

\section{References}

1. Papazoglou, A.J.; Elnashai, A.S. Analytical and field evidence of the damaging effect of vertical earthquake ground motion. Earthq. Eng. Struct. D 1996, 25, 1109-1137. [CrossRef]

2. Elnashai, A.S.; Papazoglou, A.J. Procedure and spectra for analysis of RC structures subjected to strong vertical earthquake loads. J. Earthq. Eng. 1997, 1, 121-155. [CrossRef]

3. Kim, S.J.; Elnashai, A.S. Seismic assessment of RC structures considering vertical ground motion. Mid-Am. Earthq. Cent. CD 2008. Available online: https:/ / www.ideals.illinois.edu/handle/2142/9454 (accessed on 20 February 2021).

4. Kim, S.J.; Holub, C.J.; Elnashai, A.S. Analytical assessment of the effect of vertical earthquake motion on RC bridge piers. J. Struct. Eng. 2011, 137, 252-260. [CrossRef]

5. Kunnath, S.K.; Erduran, E.; Chai, Y.H.; Yashinsky, M. Effect of near-fault vertical ground motions on seismic response of highway overcrossings. J. Bridge. Eng. 2008, 13, 282-290. [CrossRef]

6. Pozos-Estrada, A.; Chávez, M.M.; Jaimes, M.Á.; Arnau, O.; Guerrero, H. Damages observed in locations of Oaxaca due to the Tehuantepec Mw8. 2 earthquake, Mexico. Nat. Hazards 2019, 97, 623-641. [CrossRef]

7. Valdés-Vázquez, J.G.; García-Soto, A.D.; Luna-Rodríguez, F.J.; Valdés-Vázquez, J.F.; Hernández-Martínez, A. Modal analysis of structures using consistent mass matrices instead of concentrated mass matrices (In Spanish). In Proceedings of the XXI National Conference of Earthquake Engineering, Monterrey, NL, Mexico, 20-23 November 2019.

8. Paz, M.; Kim, Y.H. Structural Dynamics Theory and Computation; Springer International Publishing: Cham, Switzerland, 2019.

9. Bozorgnia, Y.; Campbell, K.W. Ground Motion Model for the Vertical-to-Horizontal (V/H) Ratios of PGA, PGV, and response spectra. Earthq. Spectra. 2016, 32, 951-978. [CrossRef]

10. Jaimes, M.A.; Ruiz-García, J. New vertical-to-horizontal ratio spectrum due to intraslab earthquakes for soft-soil sites of Mexico City. Soil Dyn. Earthq. Eng. 2019, 126, 105804. [CrossRef]

11. Di Michele, F.; Cantagallo, C.; Spacone, E. Effects of the vertical seismic component on seismic performance of an unreinforced masonry structures. B Earthq. Eng. 2020, 18, 1635-1656. [CrossRef]

12. Ruiz-García, J. Examination of the vertical earthquake ground motion component during the September 19, $2017(\mathrm{Mw}=7.1)$ earthquake in Mexico City. Soil Dyn. Earthq. Eng. 2018, 110, 13-17. [CrossRef]

13. Badalouka, B.G.; Papadopoulos, G.A. Experimental Study of a Structure Under Stress Pulse Simulating Vertical Ground Motion. J. Earthq. Eng. 2008, 12, 341-356. [CrossRef]

14. Dolatshahi, K.M.; Rezaie, A.; Rafiee-Dehkharghani, R. Topology Optimization of Wave Barriers for Mitigation of Vertical Component of Seismic Ground Motions. J. Earthq. Eng. 2020, 24, 84-108. [CrossRef]

15. Gremer, N.; Adam, C.; Medina, R.A.; Moschen, L. Vertical peak floor accelerations of elastic moment-resisting steel frames. $B$ Earthq. Eng. 2019, 17, 3233-3254. [CrossRef]

16. Jaimes, M.A.; García-Soto, A.D. Updated ground motion prediction model for Mexican intermediate-depth intraslab earthquakes including V/H ratios. Earthq. Spectra. 2020, 36, 1298-1330. [CrossRef]

17. Liberatore, D.; Doglioni, C.; AlShawa, O.; Atzori, S.; Sorrentino, L. Effects of coseismic ground vertical motion on masonry constructions damage during the 2016 Amatrice-Norcia (Central Italy) earthquakes. Soil Dyn. Earthq. Eng. 2019, 120, 423-435. [CrossRef]

18. Yang, H.; Yin, X. Transient responses of girder bridges with vertical poundings under near-fault vertical earthquake. Earthq. Eng. Struct. D. 2015, 44, 2637-2657. [CrossRef]

19. Dehghanpoor, A.; Thambiratnam, D.; Chan, T.; Taciroglu, E.; Kouretzis, G.; Li, Z. Coupled Horizontal and Vertical Component Analysis of Strong Ground Motions for Soil-Pile-Superstructure Systems: Application to a Bridge Pier with Soil-Structure Interaction. J. Earthq. Eng. 2019. [CrossRef] 
20. Chen, Y.; Kun, K.; Larkin, T.; Chouw, N. Impact of Vertical Ground Excitation on a Bridge with Footing Uplift. J. Earthq. Eng. 2016, 20, 1035-1053. [CrossRef]

21. Gülerce, Z.; Abrahamson, N.A. Vector-Valued Probabilistic Seismic Hazard Assessment for the Effects of Vertical Ground Motions on the Seismic Response of Highway Bridges. Earthq. Spectra. 2010, 26, 999-1016. [CrossRef]

22. Di Sarno, L.; Elnashai, A.S.; Manfredi, G. Assessment of RC Columns Subjected to Horizontal and Vertical Ground Motions Recorded During the 2009 L'Aquila (Italy) Earthquake. Eng. Struct. 2011, 33, 1514-1535. [CrossRef]

23. Mazza, F.; Vulcano, A. Effects of Near-Fault Ground Motions on the Nonlinear Dynamic Response of Base-Isolated RC Framed Buildings. Earthq. Eng. Struct. D 2012, 41, 211-232. [CrossRef]

24. Landi, L.; Grazi, G.; Diotallevi, P.P. Comparison of Different Models for Friction Pendulum Isolators in Structures Subjected to Horizontal and Vertical Ground Motions. Soil Dyn. Earthq. Eng. 2016, 81, 75-83. [CrossRef]

25. Mazza, F.; Mazza, M. Nonlinear Seismic Analysis of Irregular RC Framed Buildings Base-Isolated with Friction Pendulum System under Near-Fault Excitations. Soil Dyn. Earthq. Eng. 2016, 90, 299-312. [CrossRef]

26. Harrington, C.C.; Liel, A.B. Collapse assessment of moment frame buildings, considering vertical ground shaking. Earthq. Eng. Struct. D 2016, 45, 2475-2493. [CrossRef]

27. Housner, G.W. Spectrum intensities of strong motion earthquakes. In Proceedings of the Symposium on Earthquakes and Blast Effects on Structures, Los Angeles, CA, USA, June 1952; Earthquake Engineering Research Institute: Los Angeles, CA, USA; pp. 20-36.

28. American Society of Civil Engineers (ASCE). ASCE Standard-ASCE/SEI 7-16: Minimum Design Loads for Buildings and Other Structures; ASCE: New York, NY, USA, 2016.

29. IBC-2018 International Building Code; International Code Council: Country Club Hills, IL, USA, 2018.

30. NTCS-2017 Normas Técnicas Complementarias para Diseño por Sismo, Reglamento de Construcciones para el Distrito Federal, Gaceta Oficial del Departamento del Distrito Federal. 2017. (In Spanish)

31. Eurocode. Eurocode 8: Design of Structures for Earthquake Resistance-Part 1: General Rules, Seismic Actions and Rules for Buildings; The National Standards Authority of Ireland: Dublin, Ireland, 2004.

32. Mazzoni, S.; McKenna, F.; Scott, M.H.; Fenves, G.L. OpenSees Command Language Manual. University of California, Berkeley. Available online: https:/ / opensees.berkeley.edu/ (accessed on 29 December 2020).

33. GiD. The Personal Pre- and Post-Processor. CIMNE, www.gidhome.com, 15th Eds. Available online: https://www.gidhome.com/ (accessed on 29 December 2020).

34. GiD+OpenSEES v.2.8.0. An Integrated FEA Platform. Lab of R/C and Masonry Structures, School of Civil Engineering, AUTh, Greece. Available online: http:/ /gidopensees.rclab.civil.auth.gr/ (accessed on 29 December 2020).

35. American Society of Civil Engineers Standard. Seismic Evaluation and Retrofit of Existing Buildings 41-17; American Society of Civil Engineers: Reston Town Center, VA, USA, 2017.

36. Roeder, C.W.; Schneider, S.P.; Carpenter, J.D. Seismic behavior of moment-resisting steel frames: Analytical investigation. J. Struct. Engrg. 1993, 119, 1866-1884. [CrossRef]

37. Schneider, S.P.; Roeder, C.W.; Carpenter, J.E. Behavior of moment resisting steel frames: Experimental investigation. J. Struct. Engrg. 1993, 119, 1885-1902. [CrossRef]

38. ICBO. Uniform Building Code; International Conference of Building Officials: Whittier, CA, USA, 1988. 